\title{
Design and Synthesis of Disulfide-Rich Peptides with Orthogonal Disulfide Pairing Motifs
}

Zirong Huang, Yapei Wu, Huilei Dong, Yibing Zhao, and Chuanliu Wu*

Department of Chemistry, College of Chemistry and Chemical Engineering, The MOE Key Laboratory of Spectrochemical Analysis and Instrumentation, Xiamen University, Xiamen 361005, People's Republic of China.

*To whom correspondence should be addressed, Email: chlwu@xmu.edu.cn 


\section{Table of Contents}

Table S1. Sequence Information of All the Synthesized Peptides

1. Tryptic Digestion Mass Spectral Analysis of the Products of Peptide 1

2. Analysis of Disulfide Pairing of Peptide 2 Through the Orthogonal Protecting Group Strategy

3. Oxidative Folding and Tryptic Digestion Mass Spectral Analysis of the Oxidative Product of Peptide 3 S9

4. Oxidative Folding of Peptide 2 in PB Buffer in the Absence of $\mathbf{G u} \cdot \mathbf{H C l}$ S11

5. Analysis of Disulfide Pairing of Peptides 4, 5, 7 and 8 Through the Orthogonal Protecting Group Strategy S12

6. Oxidative Folding and Tryptic Digestion Mass Spectral Analysis of the Oxidative Products of Peptide 6 S15

7. Oxidative Folding of Peptide 9 S18

8. Analysis of Disulfide Pairing of Peptide 9 Through the Orthogonal Protecting Group Strategy S19

9. The Inhibition of U87MG Cell Adhesion S20

10. Oxidative Folding of Peptide 10 S21

11. Analysis of Disulfide Pairing of Peptide 10 Through the Orthogonal Protecting Group Strategy S22

12. Oxidative Folding of Peptide 11 S23

13. Analysis of Disulfide Pairing of Peptide 11 Through the Orthogonal Protecting Group Strategy . S24

14. Kinetics of Peptide 10 and 11 Degradation by Chymotrypsin in Tris-HCl Buffer at pH 7.8 . $\mathrm{S} 25$

15. Oxidative Folding of Peptide 12 and 13 in GSSG Buffers S26

16. Analysis of Disulfide Pairing of Peptide 12 Through the Orthogonal Protecting Group Strategy and Tryptic Digestion S27

17. Analysis of Disulfide Pairing of Peptide 13 Through the Orthogonal Protecting Group Strategy and Tryptic Digestion . S30 
Results

Table S1. Sequence Information of All the Synthesized Peptides

\begin{tabular}{|c|c|}
\hline Name & Sequence \\
\hline Peptide 1 & WGCKPenKCGGKWGPenGKGWGPenGGKGGCGW-NH ${ }_{2}$ \\
\hline Peptide2 & WGCGGKGGPenGGWKGPenGCGPenGCGW-NH ${ }_{2}$ \\
\hline Peptide 3 & WGCGGKGGPenGGWKGPenKCKPenKCGW-NH ${ }_{2}$ \\
\hline Peptide4 & WGCGPenGCGPenGGKGGCGGWKGPenGW-NH ${ }_{2}$ \\
\hline Peptide 5 & WGPenGGKGGPenGCGPenGCGGWKGCGW-NH ${ }_{2}$ \\
\hline Peptide 6 & WGCGGKGGPenGCGPenGCGGWKGPenGW-NH ${ }_{2}$ \\
\hline Peptide 7 & WGCGGKGGPenGGWKGCGPenGCGPenGW-NH ${ }_{2}$ \\
\hline Peptide 8 & WGPenGGKGGCGGWKGPenGCGPenGCGW-NH ${ }_{2}$ \\
\hline Peptide 9 & WGPenGRGDYGPenGCGPenGCGRGDYGCGW-NH $_{2}$ \\
\hline Peptide 10 & KGCGPenGCGPenLDEETGEFLPenGGKGGCGW-NH ${ }_{2}$ \\
\hline Peptide 11 & KGPenGGKGGPenGCGPenGCEAALSQETFSDLWKLLAENNVLSCGK-NH ${ }_{2}$ \\
\hline Peptide 12 & WGCpPenKcPenGGKGGPenGGWKGCGW-NH ${ }_{2}$ \\
\hline Peptide 13 & WGPenGGKGGCpPenKcPPenGGWKGCGW-NH ${ }_{2}$ \\
\hline Peptide S2 & WGCGGKGGPenGGWKGPen(Acm)GCGPenGC(Acm)GW-NH ${ }_{2}$ \\
\hline Peptide S4 & WGC(Acm)GPenGCGPen(Acm)GGKGGCGGWKGPenGW-NH ${ }_{2}$ \\
\hline Peptide S5 & WGPenGGKGGPen(Acm)GCGPenGC(Acm)GGWKGCGW-NH ${ }_{2}$ \\
\hline Peptide S6 & WGCGGKGGPen(Acm)GCGPenGC(Acm)GGWKGPenGW-NH ${ }_{2}$ \\
\hline Peptide S7 & WGCGGKGGPenGGWKGC(Acm)GPenGCGPen(Acm)GW-NH ${ }_{2}$ \\
\hline Peptide S8 & WGPenGGKGGCGGWKGPen(Acm)GCGPenGC(Acm)GW-NH ${ }_{2}$ \\
\hline
\end{tabular}


Peptide S10 KGC(Acm)GPenGCGPen(Acm)LDEETGEFLPenGGKGGCGW-NH 2

Peptide S11 KGPenGGKGGPen(Acm)GCGPenGC(Acm) EAALSQETFSDLWKLLAENNVL

$$
\text { SCGK-NH }
$$

Peptide S12 WGC(Acm)pPenKcPPen(Acm)GGKGGPenGGWKGCGW-NH

Peptide S13 WGPenGGKGGC(Acm)pPenKcPPen(Acm)GGWKGCGW-NH 
1. Tryptic Digestion Mass Spectral Analysis of the Products of Peptide 1

a)

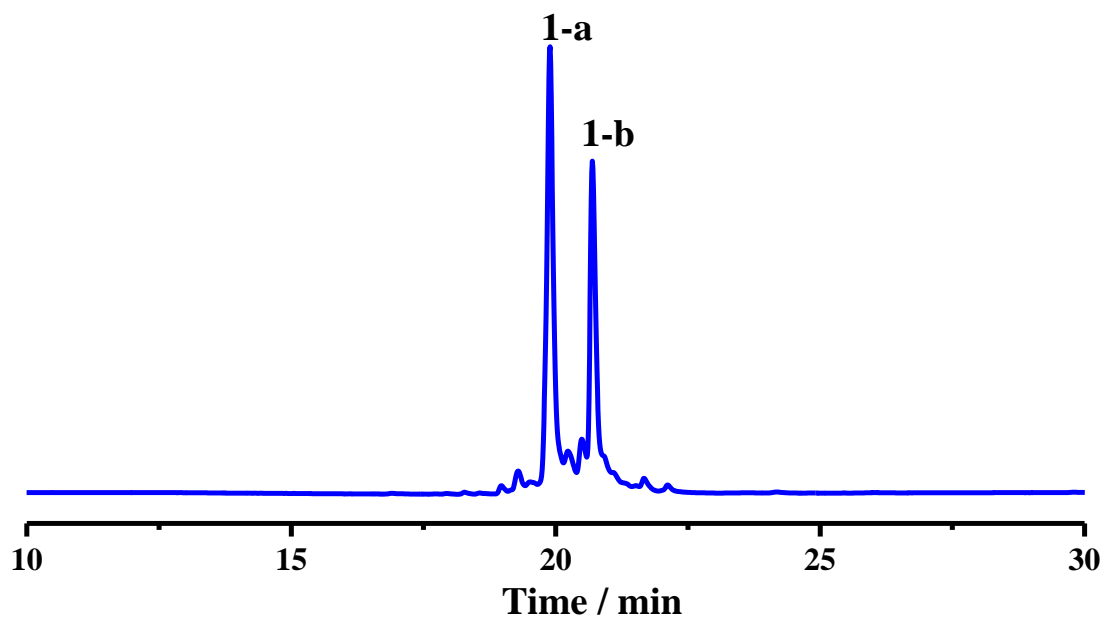

b)
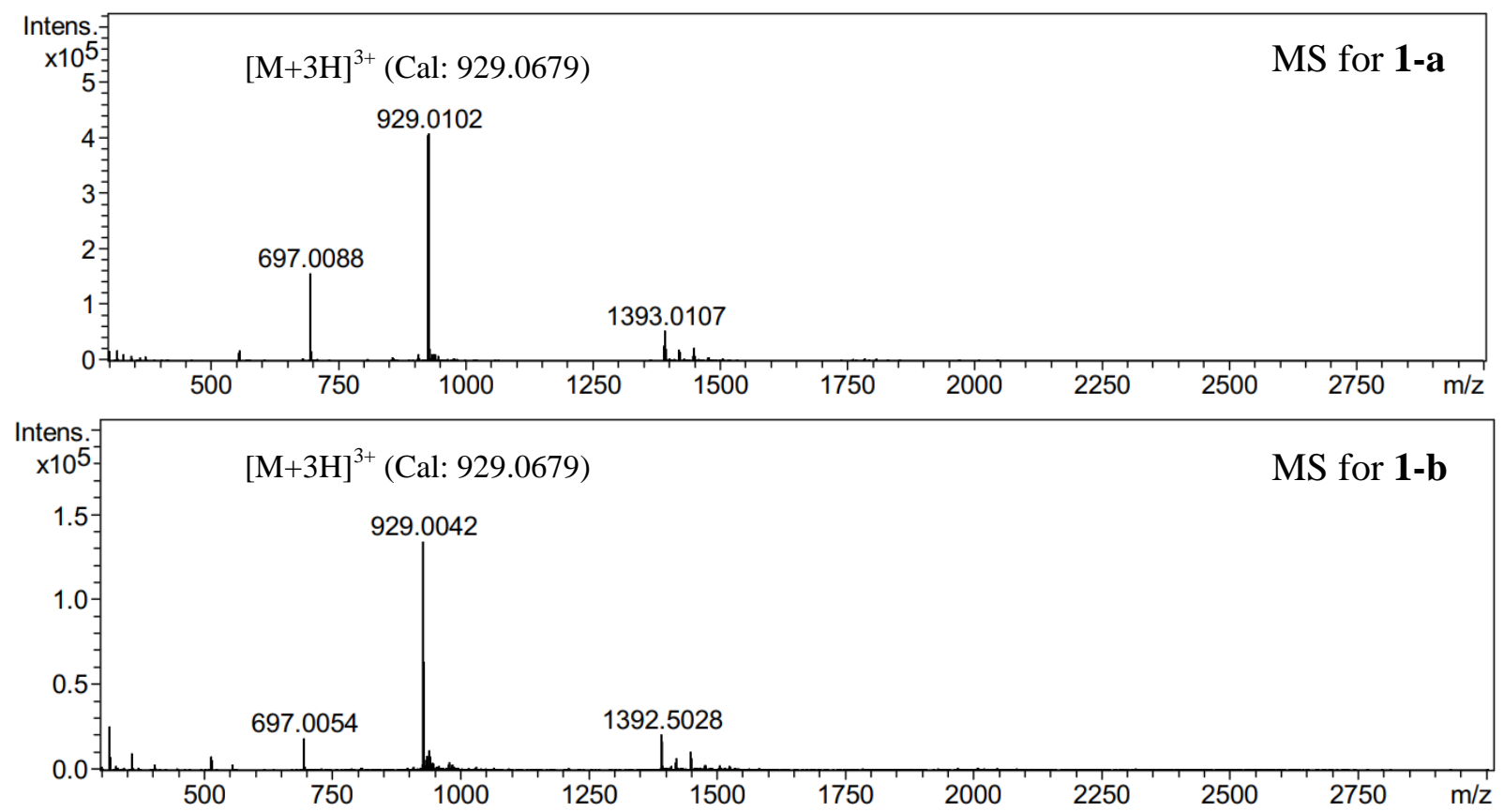

c)

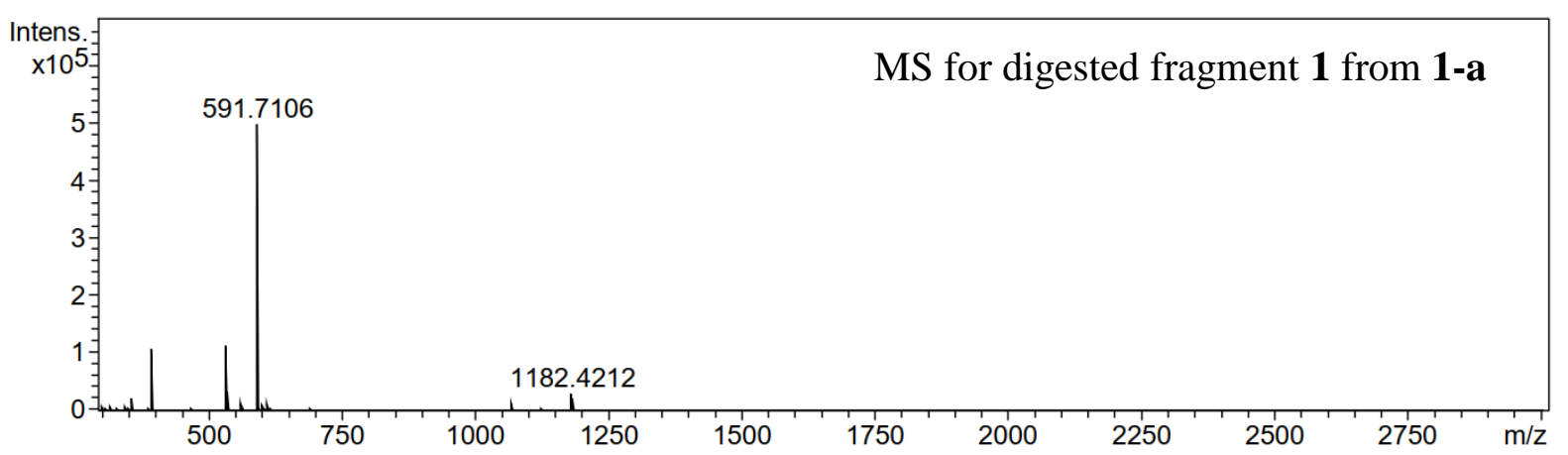



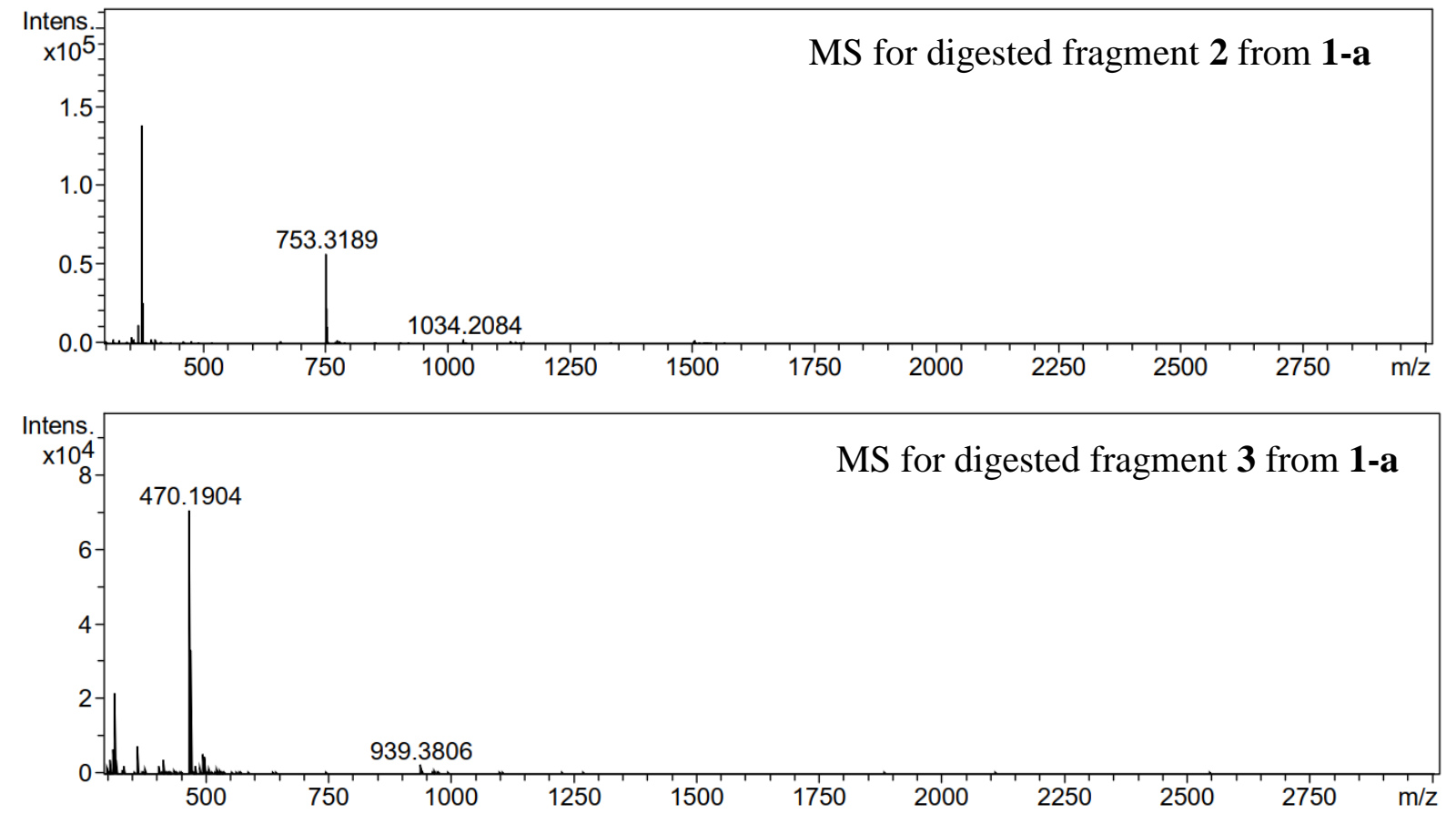

d)
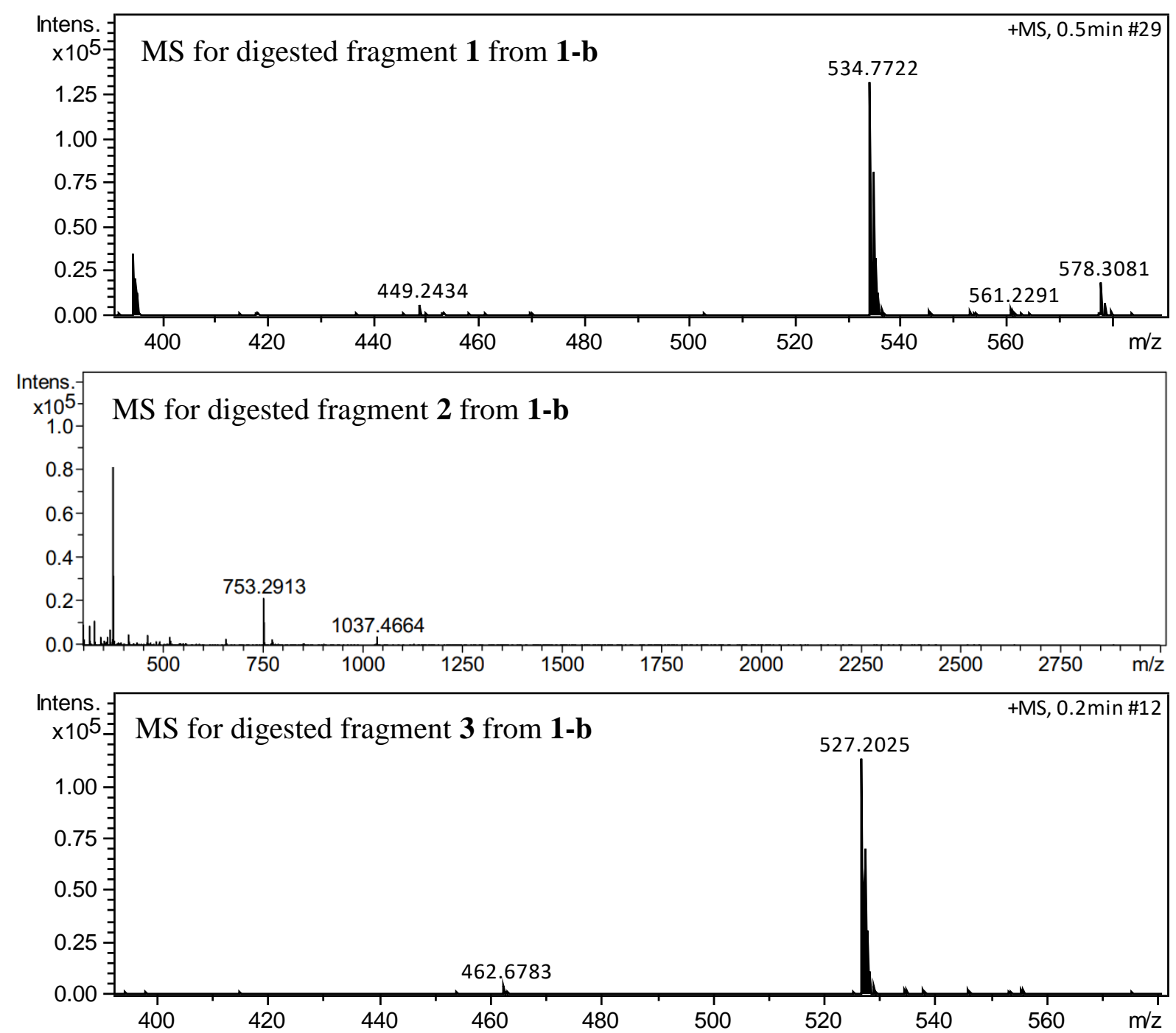
Figure S1. (a) Chromatogram of the products formed after the oxidation of peptide 1. (b) Mass spectra of the products formed after the oxidation of peptide 1. (c) Mass spectra of digested fragments from 1-a labeled in the chromatogram. (d) Mass spectra of digested fragments from 1-b labeled in the chromatogram.

The arrows indicate the cleavage sites of trypsin digestion:

\section{$\mathrm{WGC}_{1} \mathrm{~K}_{\downarrow} \operatorname{Pen}_{2} \mathrm{~K}_{\downarrow} \mathrm{C}_{3} \mathrm{GGK}_{\downarrow} \mathrm{WGPen}_{4} \mathrm{GK}_{\downarrow} \mathrm{GWGPen}_{5}$ GGK $\mathrm{GGC}_{6} \mathrm{GW}-\mathrm{NH}_{2}$}

Fragment analysis of 1-a:

\begin{tabular}{|c|c|c|c|c|}
\hline $\begin{array}{c}\text { Fragment } \\
\text { No. }\end{array}$ & $\begin{array}{l}\text { Fragment } \\
\text { sequence }\end{array}$ & $\begin{array}{l}\text { Disulfide } \\
\text { pairing }\end{array}$ & $\begin{array}{c}m / z \\
\text { calcd }\end{array}$ & $\begin{array}{c}m / z \\
\text { found }\end{array}$ \\
\hline Fragment 1 & $\underbrace{\mathrm{WGC}_{1} \mathrm{~K}}_{\text {GWGPen }_{5} \text { GGK }}$ & $1-5$ & {$[\mathrm{M}+\mathbf{2 H}]^{2+}: \mathbf{5 9 1 . 7 6 2 7}$} & {$[\mathrm{M}+2 \mathrm{H}]^{2+}: \mathbf{5 9 1 . 7 1 0 6}$} \\
\hline Fragment 2 & $\left.\right|_{\text {GGC }_{6} \text { GW-NH }} ^{\text {Pen }_{2} \mathrm{~K}}$ & $2-6$ & {$[\mathbf{M}+\mathbf{H}]^{+}: \mathbf{7 5 3 . 3 1 7 0}$} & {$[\mathrm{M}+\mathrm{H}]^{+}: \mathbf{7 5 3 . 3 1 8 9}$} \\
\hline Fragment 3 & $\begin{array}{r}\left.\right|_{\text {WGPen }_{4} \mathrm{GK}} ^{\mathrm{C}_{3} \mathrm{GGK}} \\
\end{array}$ & $3-4$ & {$[\mathrm{M}+2 \mathrm{H}]^{2+}: 470.2131$} & {$[\mathrm{M}+2 \mathrm{H}]^{2+}: 470.1904$} \\
\hline
\end{tabular}

Fragment analysis of 1-b:

\begin{tabular}{|c|c|c|c|c|}
\hline $\begin{array}{c}\text { Fragment } \\
\text { No. }\end{array}$ & $\begin{array}{l}\text { Fragment } \\
\text { sequence }\end{array}$ & $\begin{array}{c}\text { Disulfide } \\
\text { pairing }\end{array}$ & $\begin{array}{c}m / z \\
\text { calcd }\end{array}$ & $\begin{array}{c}m / z \\
\text { found }\end{array}$ \\
\hline Fragment 1 & $\begin{array}{c}\mathrm{WGC}_{1} \mathrm{~K} \\
\left.\right|_{\mathrm{WGPen}_{4} \mathrm{GK}}\end{array}$ & $1-4$ & {$[\mathrm{M}+2 \mathrm{H}]^{2+}: \mathbf{5 3 4 . 7 4 1 3}$} & {$[\mathrm{M}+2 \mathrm{H}]^{2+}: \mathbf{5 3 4 . 7 7 2 2}$} \\
\hline Fragment 2 & $\left.\right|_{\text {GGC }_{6} \text { GW-NH }} ^{\mathrm{Pen}_{2} \mathrm{~K}}$ & $2-6$ & {$[\mathrm{M}+\mathrm{H}]^{+}: \mathbf{7 5 3 . 3 1 7 0}$} & {$[\mathrm{M}+\mathrm{H}]^{+}: \mathbf{7 5 3 . 2 9 1 3}$} \\
\hline Fragment 3 & $\begin{array}{c}\mathrm{C}_{3} \mathrm{GGK} \\
\text { GWGPen }_{5} \text { GGK }\end{array}$ & $3-5$ & {$[\mathrm{M}+2 \mathrm{H}]^{2+}: \mathbf{5 2 7 . 2 3 3 9}$} & {$[\mathrm{M}+2 \mathrm{H}]^{2+}: \mathbf{5 2 7 . 2 0 2 5}$} \\
\hline
\end{tabular}


2. Analysis of Disulfide Pairing of Peptide 2 Through the Orthogonal Protecting Group Strategy

a)

Peptide 2:

WGCGGKGGPenGGWKGPenGCGPenGCGW-NH

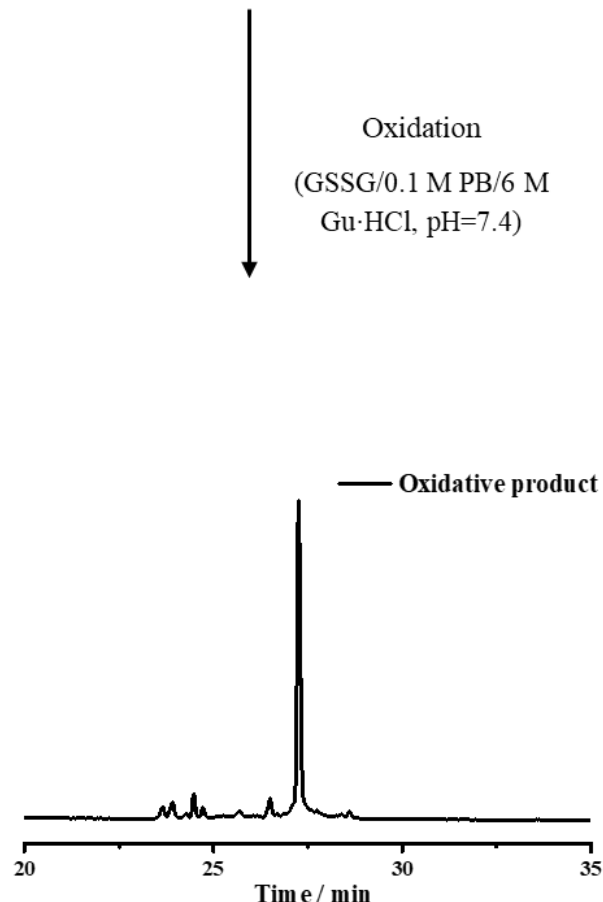

Peptide S2:

WGCGGKGGPenGGWKGPen(Acm)GCGPenGC(Acm)GW-NH

Orthogonal disulfide pairing

( $25 \% \mathrm{v} / \mathrm{v}$ DMSO)

Oxidative peptide S2:

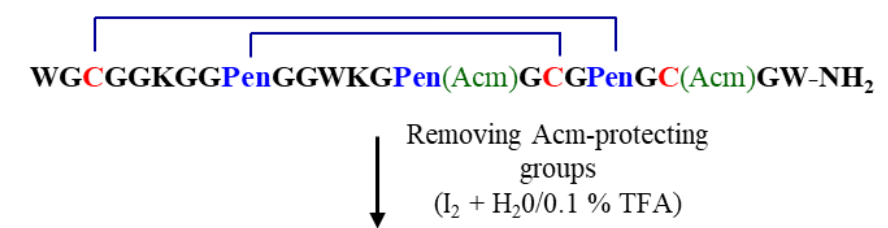

Standard product $(1-5,2-4,3-6)$ :

WGCGGKGGPenGGWKGPenGCGPenGCGW-NH

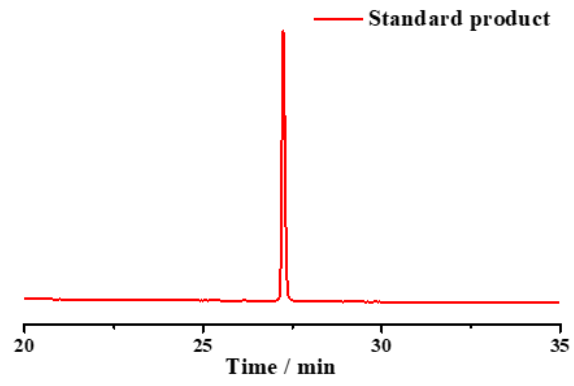

Comparing the retention time of oxidative and standard product

Standard product of 2

$(1-5,2-4,3-6)$

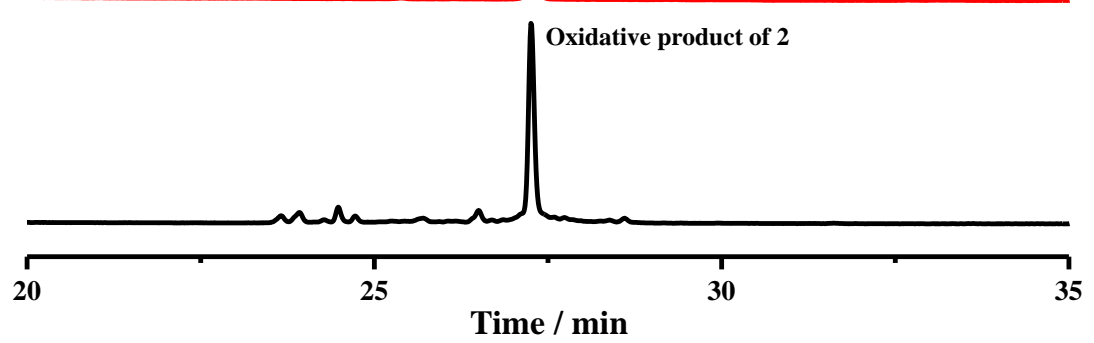


b)
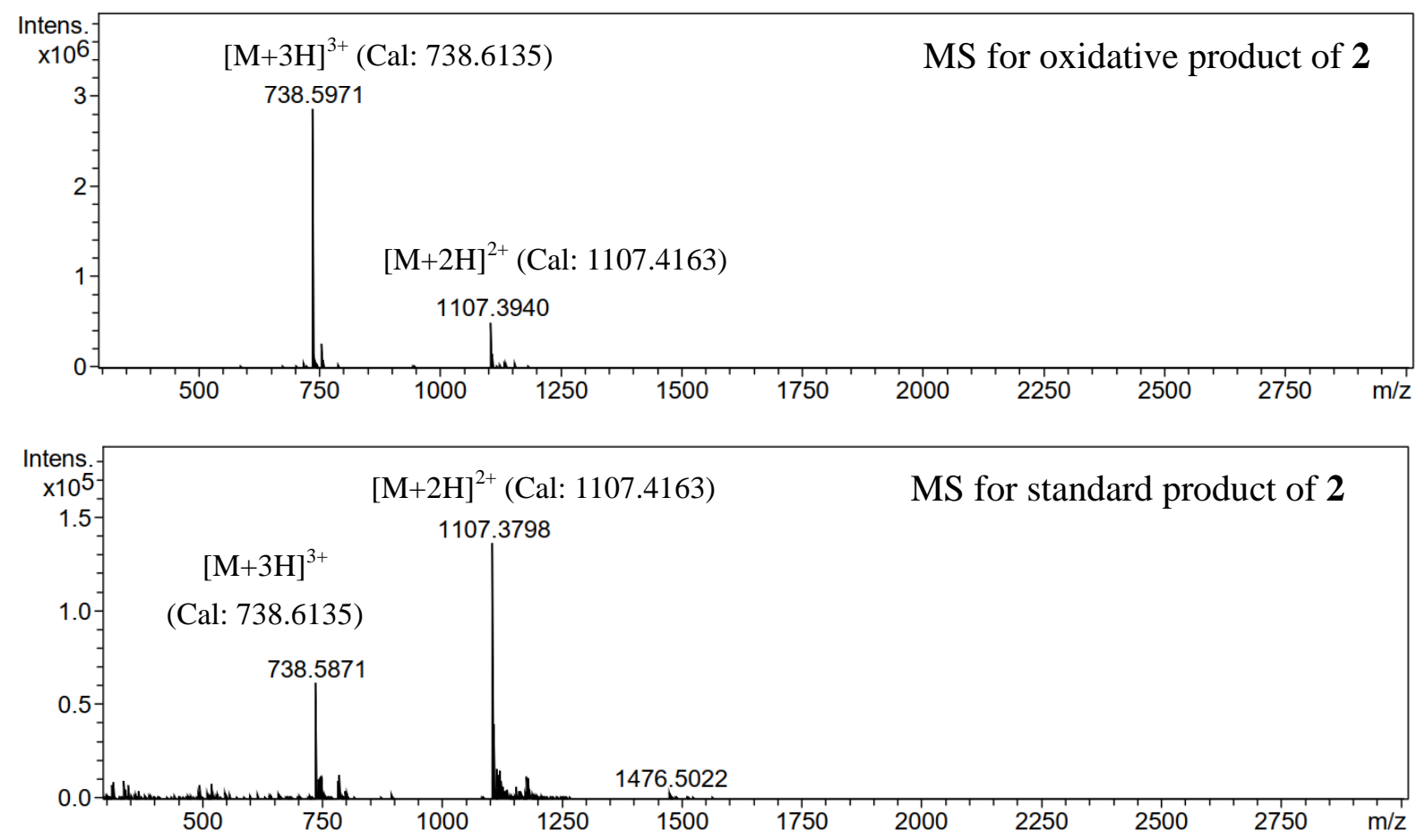

Figure S2. (a) The flowchart shows the procedures of analyzing disulfide pairing through the orthogonal protecting group strategy (tanking peptide 2 as an example); (black line) oxidative product; (red line) standard product. (b) Mass spectra of oxidative product and standard product of peptide 2. 


\section{Peptide 3}

a)

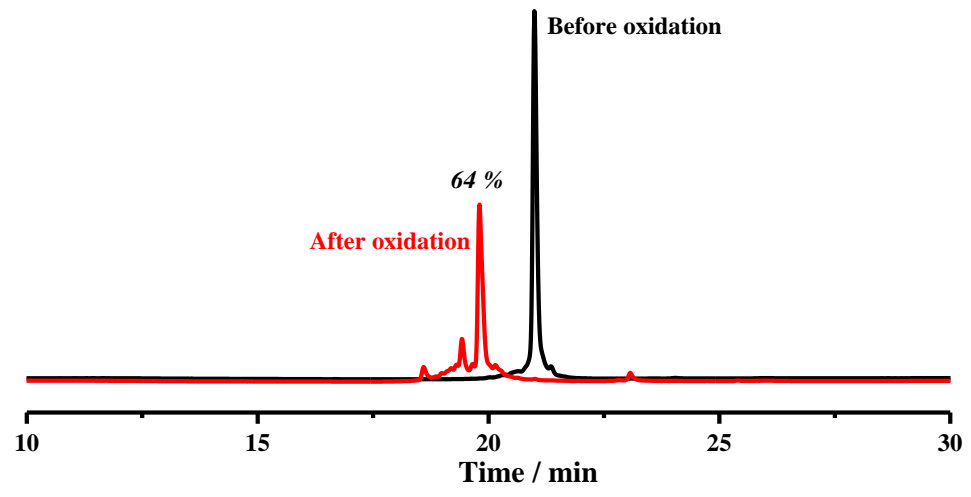

b)

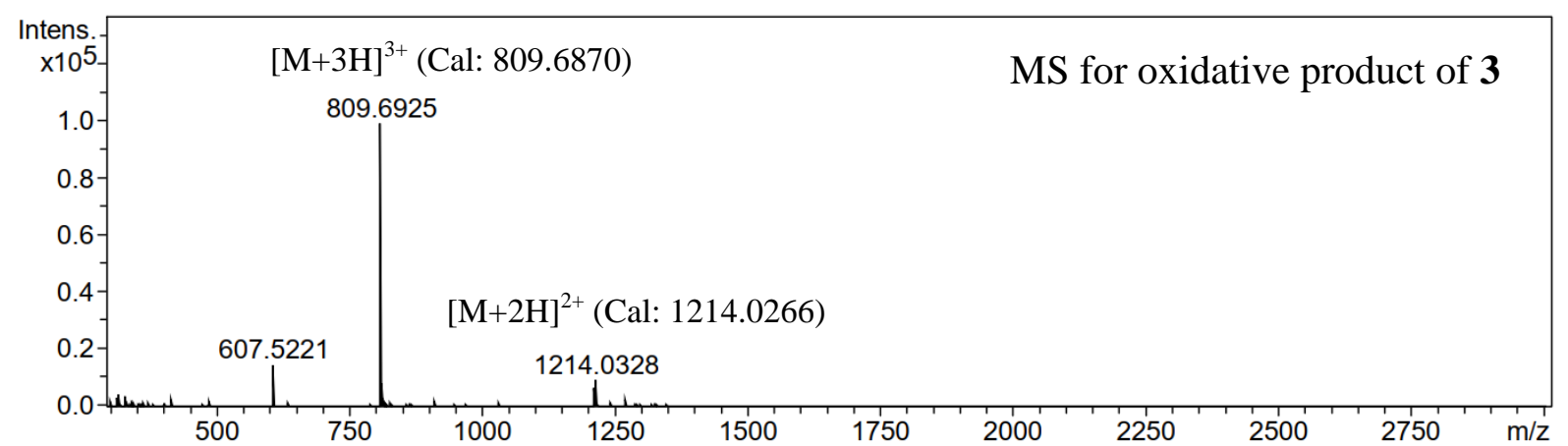

c)

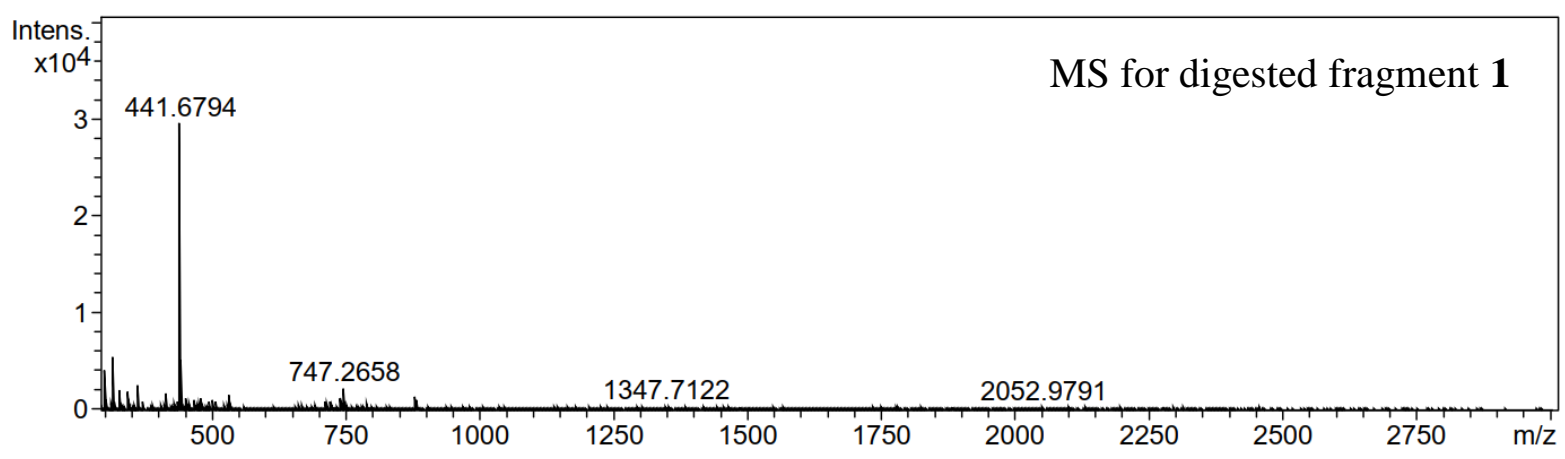



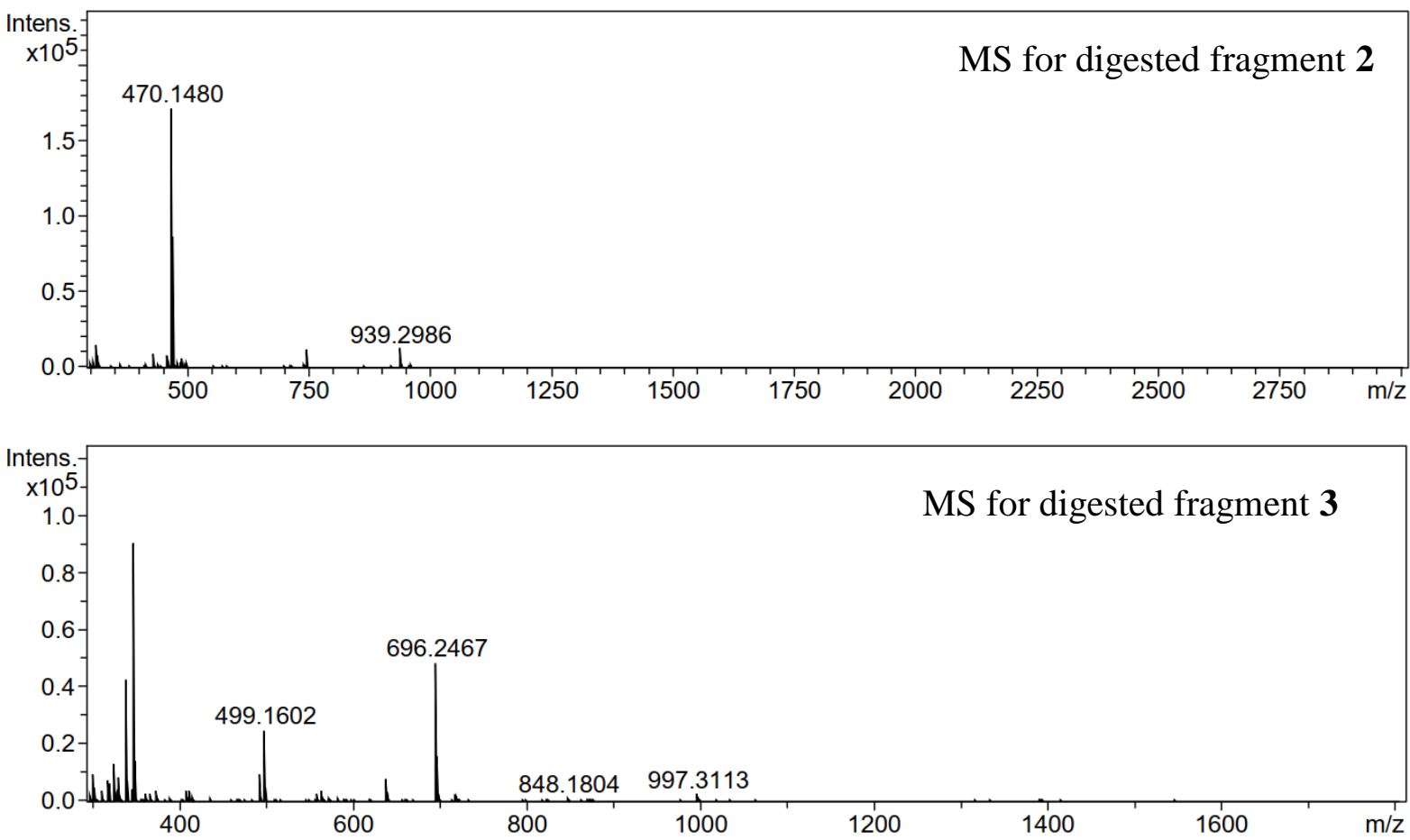

Figure S3. (a) Chromatogram of oxidative folding of peptide 3 in $100 \mathrm{mM}$ phosphate buffers containing 6 $\mathrm{M} \mathrm{Gu} \cdot \mathrm{HCl}$ and $0.5 \mathrm{mM}$ GSSG; (black line) reduced peptide; (red line) oxidative product; yield was calculated by comparing to the peak area of the reducing peptide. (b) MS characterization of the product formed after the oxidation of peptide 3. (c) Mass spectra of digested fragments from oxidative peptide 3.

The arrows indicate the cleavage sites of trypsin digestion:

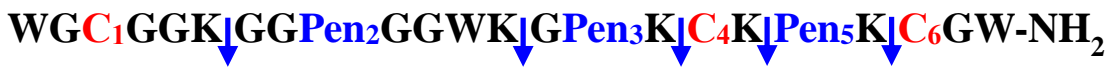

Fragment analysis:

\begin{tabular}{|c|c|c|c|c|}
\hline $\begin{array}{c}\text { Fragment } \\
\text { No. }\end{array}$ & $\begin{array}{l}\text { Fragment } \\
\text { sequence }\end{array}$ & $\begin{array}{c}\text { Disulfide } \\
\text { pairing }\end{array}$ & $\begin{array}{c}m / z \\
\text { calcd }\end{array}$ & $\begin{array}{c}m / z \\
\text { found }\end{array}$ \\
\hline Fragment 1 & $\left.\right|_{\operatorname{Pen}_{5} K} ^{\text {WGC }_{1} \text { GGK }}$ & $1-5$ & {$[\mathrm{M}+2 \mathrm{H}]^{2+}: 441.7016$} & {$[\mathrm{M}+2 \mathrm{H}]^{2+}: 441.6794$} \\
\hline Fragment 2 & $\underset{\mathrm{C}_{4} \mathrm{~K}}{\mathrm{GGPen}_{2} \mathrm{GGK}}$ & $2-4$ & {$[\mathrm{M}+2 \mathrm{H}]^{2+}: 470.2123$} & {$[\mathrm{M}+2 \mathrm{H}]^{2+}: \mathbf{4 7 0 . 1 4 8 0}$} \\
\hline Fragment 3 & $\begin{array}{l}\operatorname{Pen}_{3} \mathrm{GGK} \\
\mathrm{C}_{6} \mathrm{GW}-\mathrm{NH}_{2}\end{array}$ & $3-6$ & {$[M+H]^{+}: 696.2956$} & {$[M+H]^{+}: \mathbf{6 9 6 . 2 4 6 7}$} \\
\hline
\end{tabular}




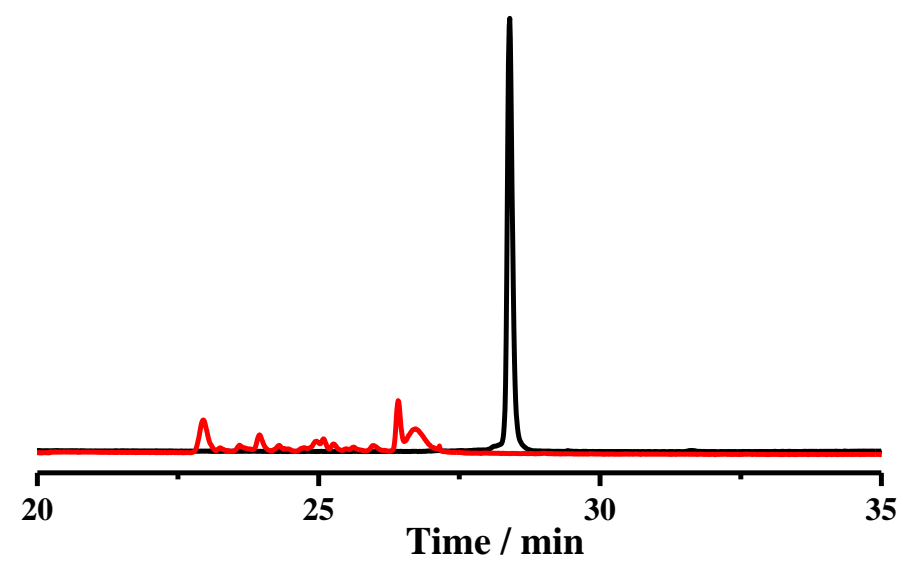

Figure S4. Chromatogram showing the oxidation of peptide 2 in $100 \mathrm{mM}$ phosphate buffers containing 0.5 mM GSSG in the absence of $\mathrm{Gu} \cdot \mathrm{HCl}$; (black line) reducing peptide; (red line) after $3 \mathrm{~h}$ oxidation. 


\section{Strategy}

a)
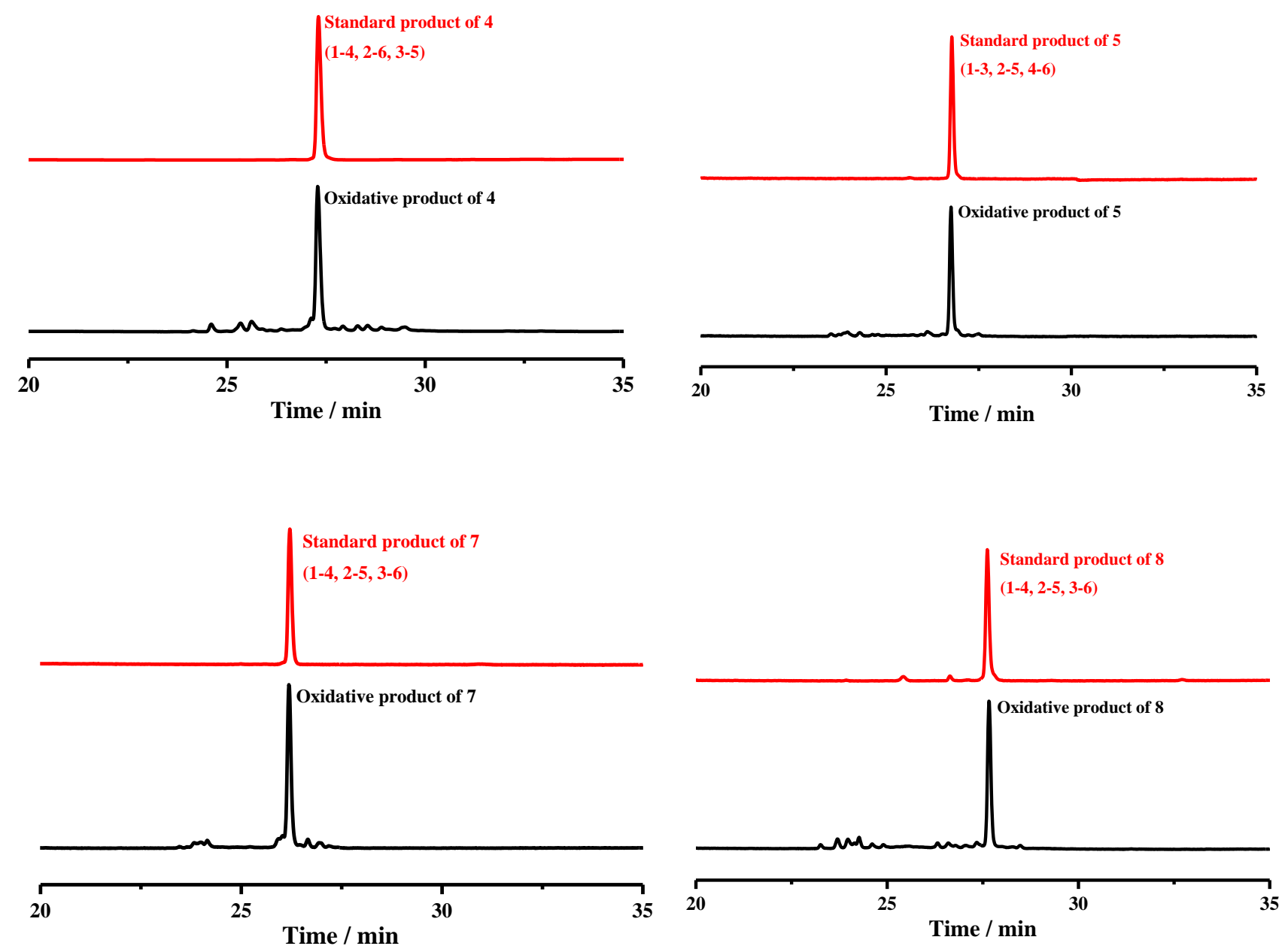

b)

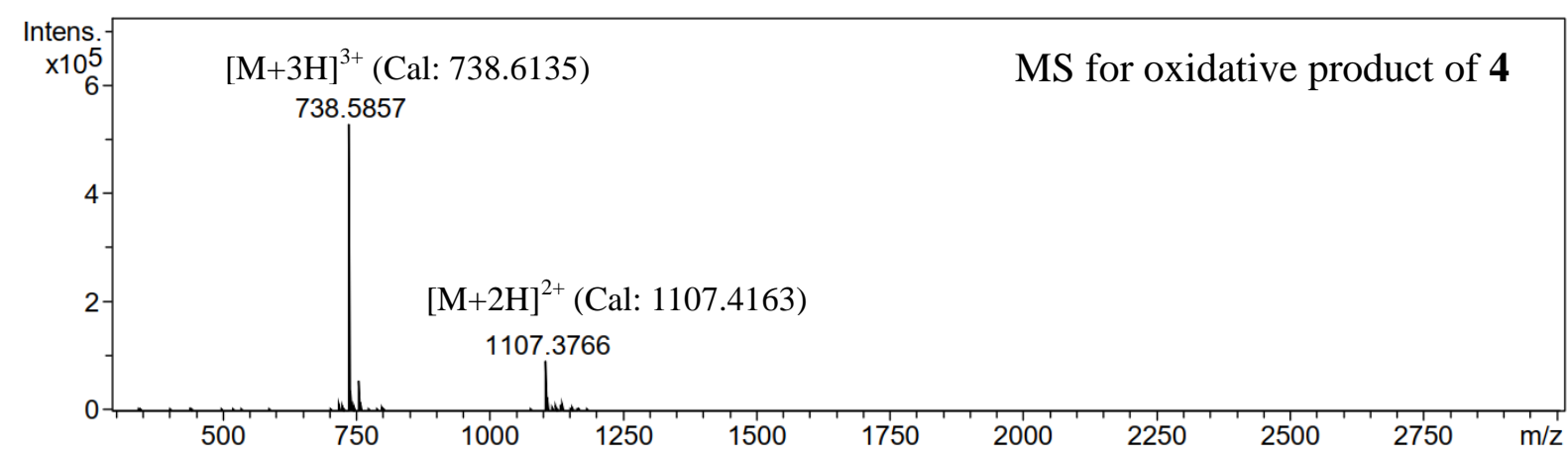



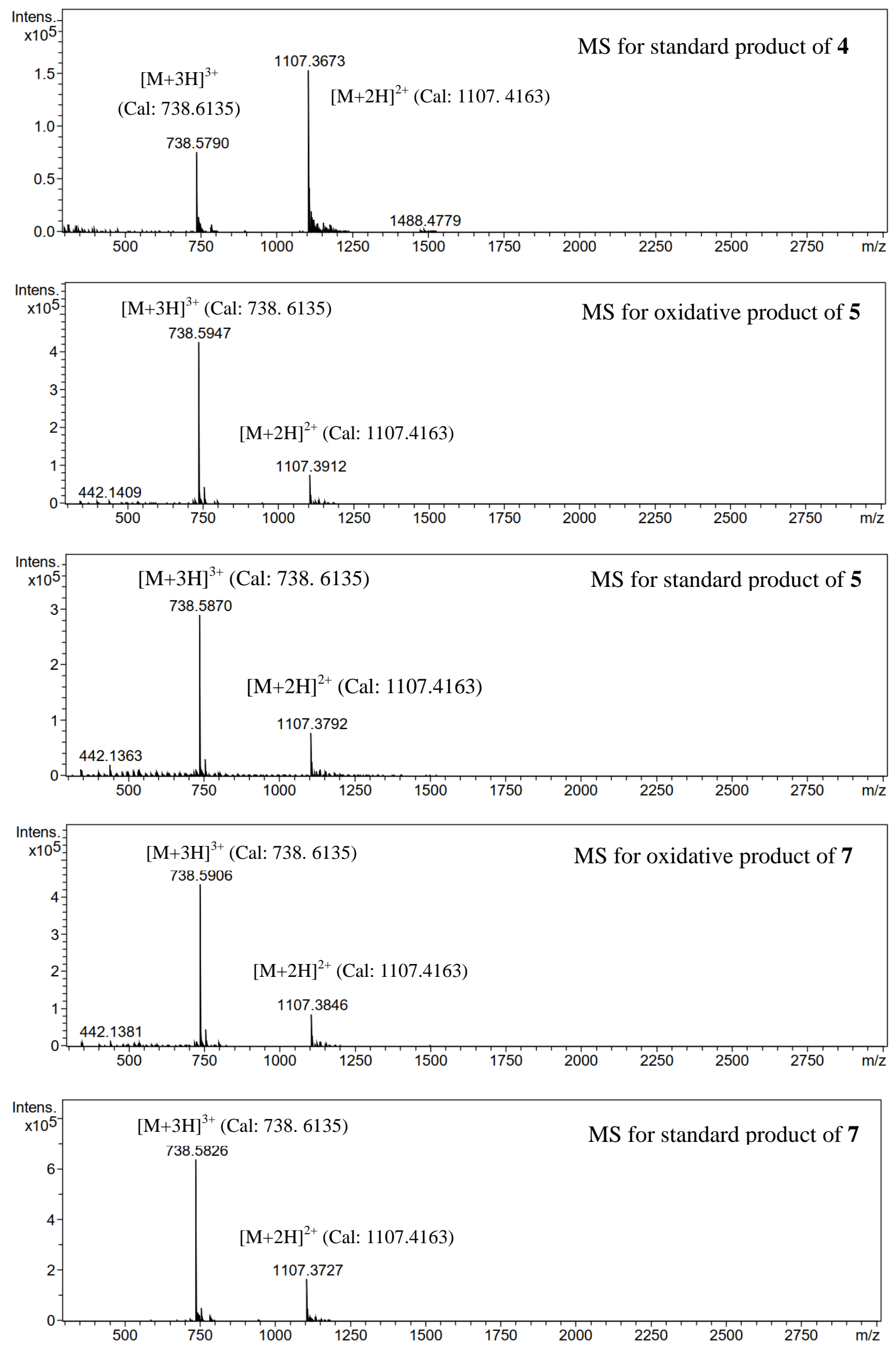

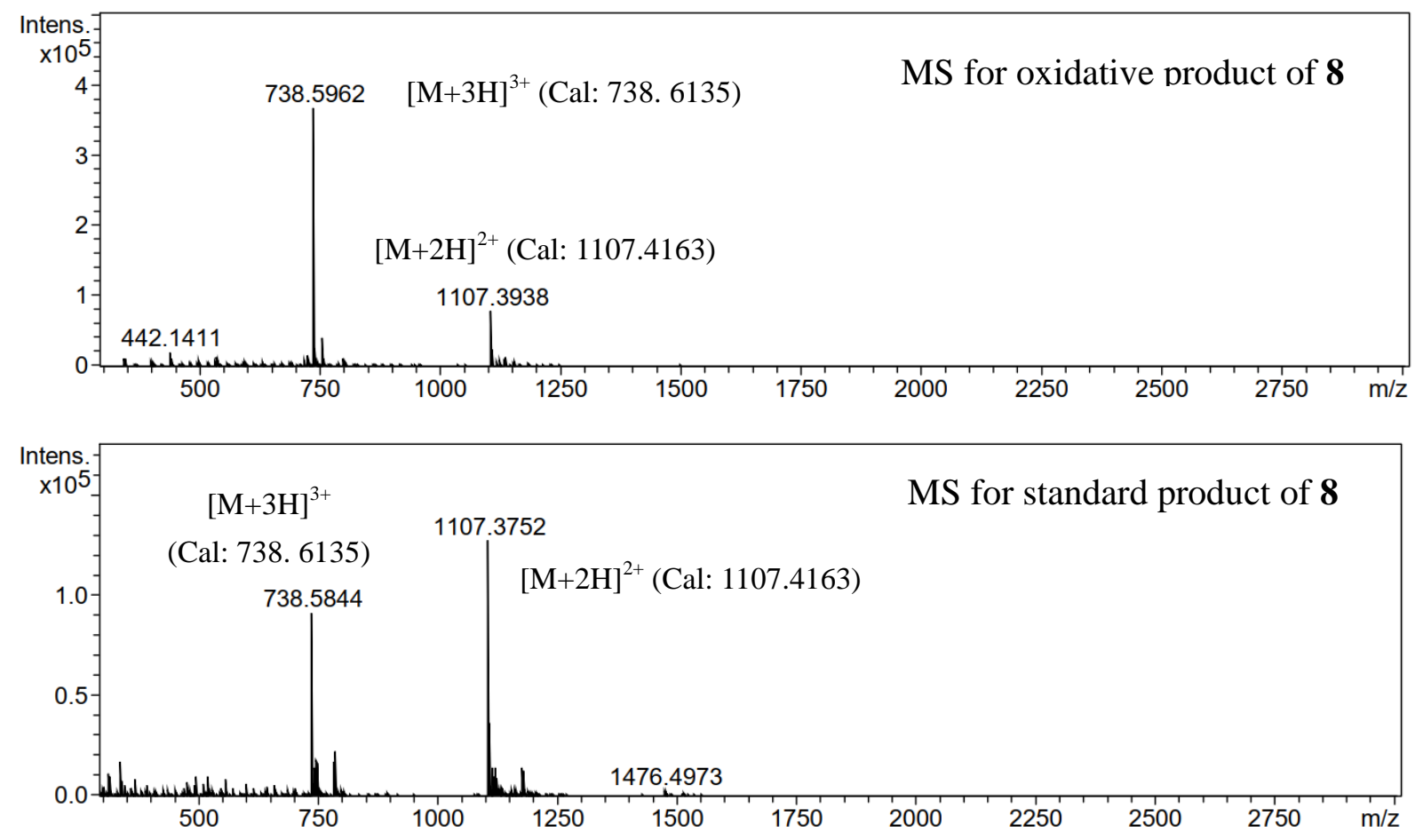

Figure S5. (a) Chromatograms showing the confirmation of disulfide connectivities within peptide 4, 5, 7 and $\mathbf{8}$ through the orthogonal protecting group strategy; (black line) oxidative product; (red line) standard product. (b) Mass spectra of oxidative products formed after the oxidation of peptide 4, 5, $\mathbf{7}$ and $\mathbf{8}$ as well as standard products produced after removing Acm groups of oxidative peptide S4, S5, S7 and S8. 
6. Oxidative Folding and Tryptic Digestion Mass Spectral Analysis of the Oxidative Products of

\section{Peptide 6}

a)

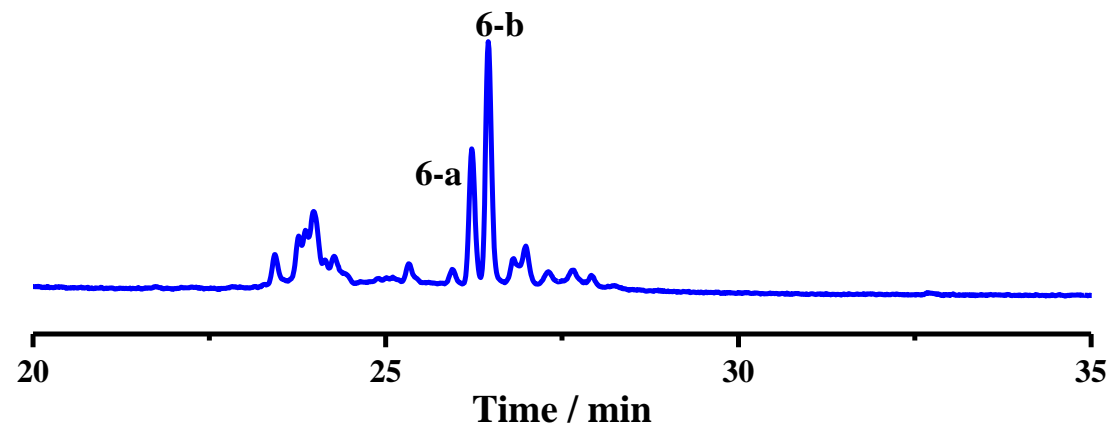

b)
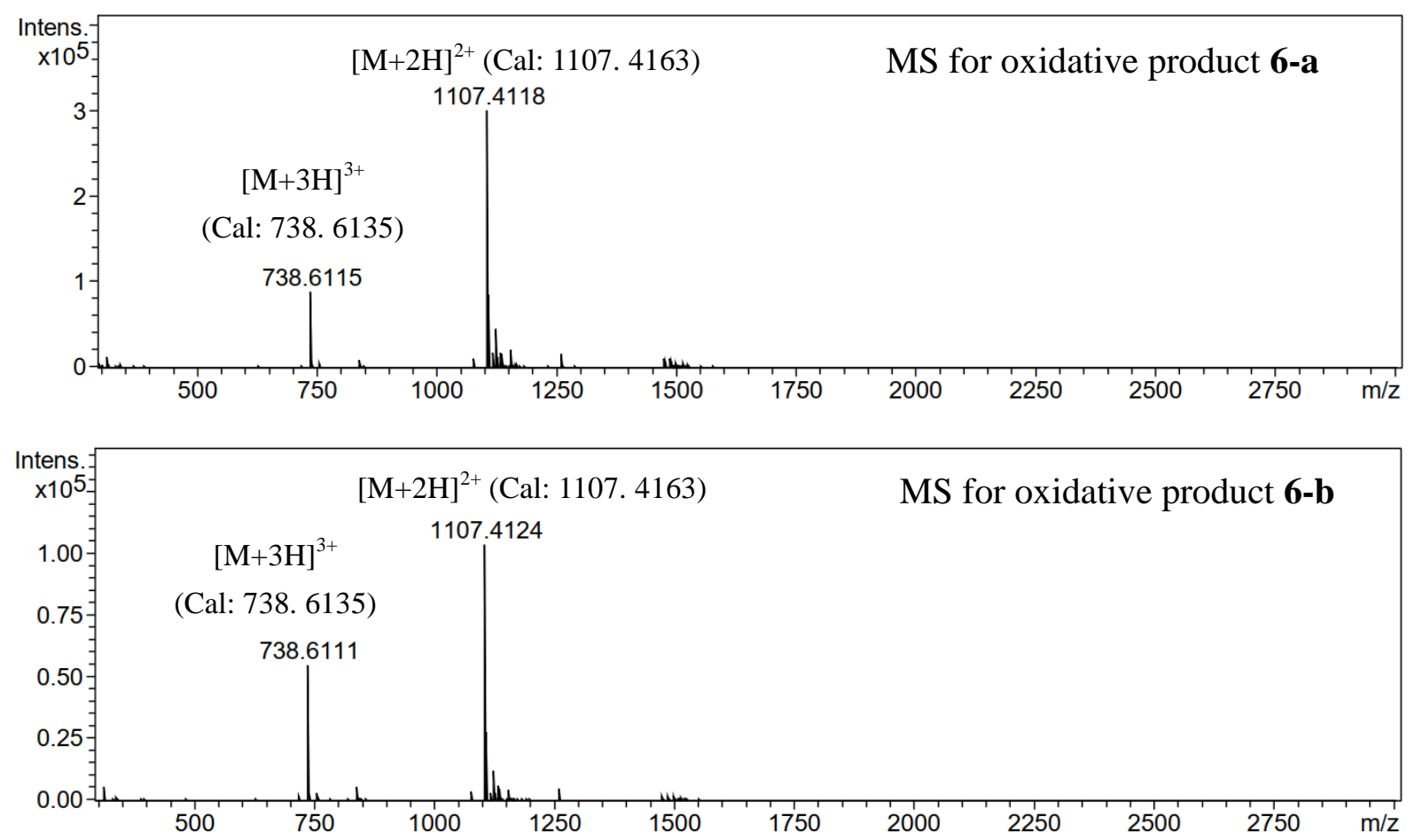

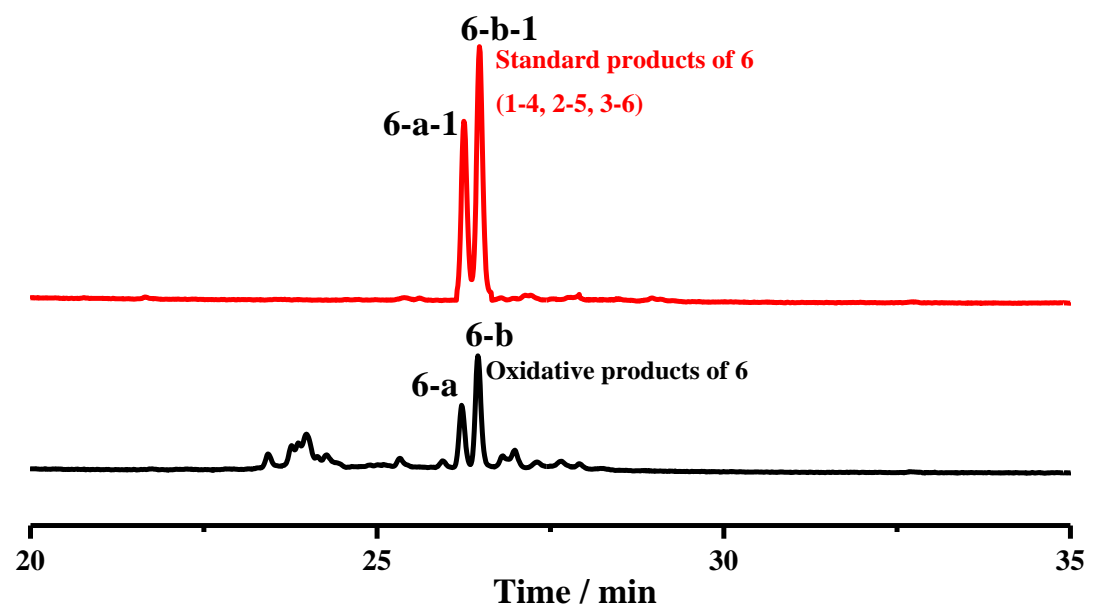

d)
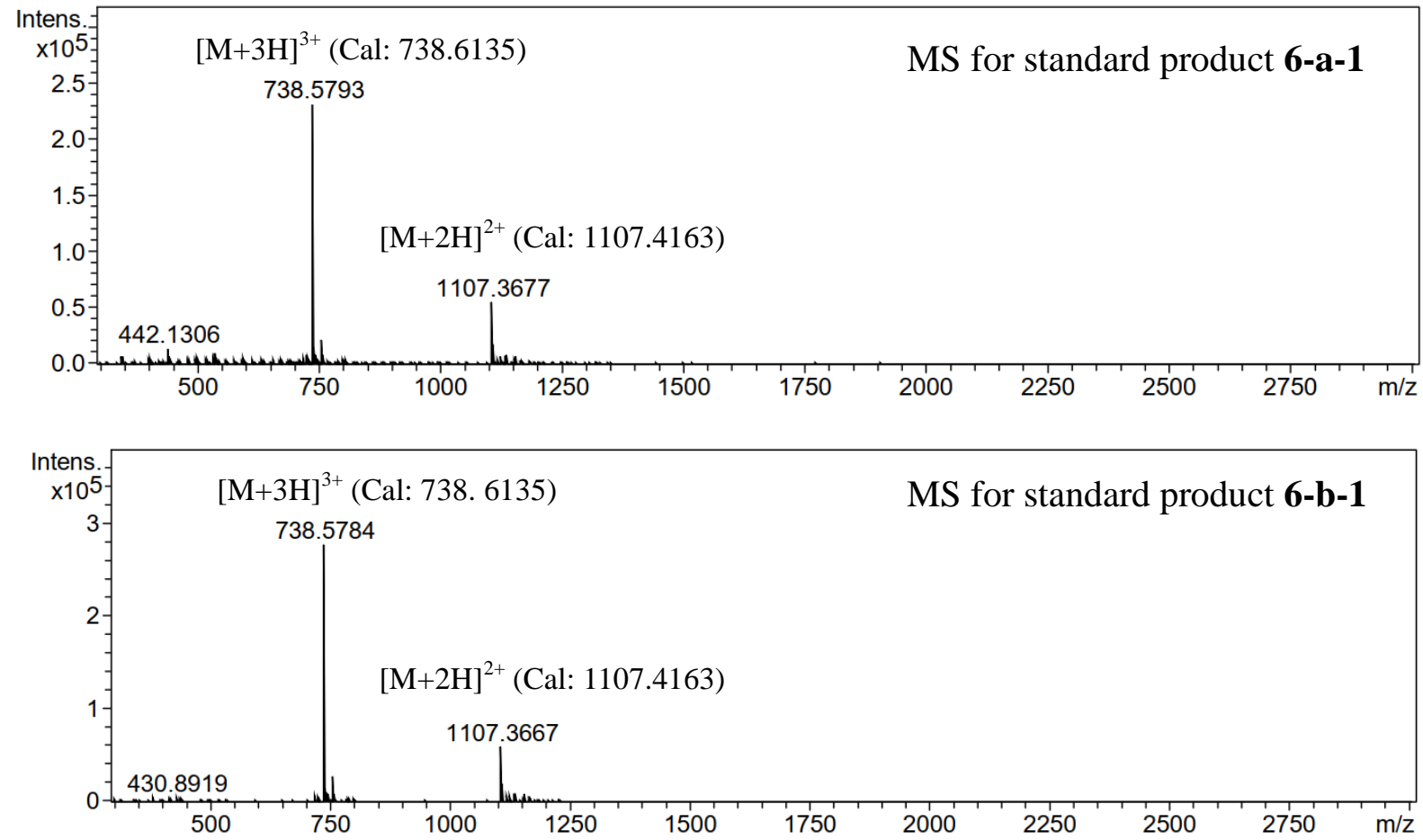

e)

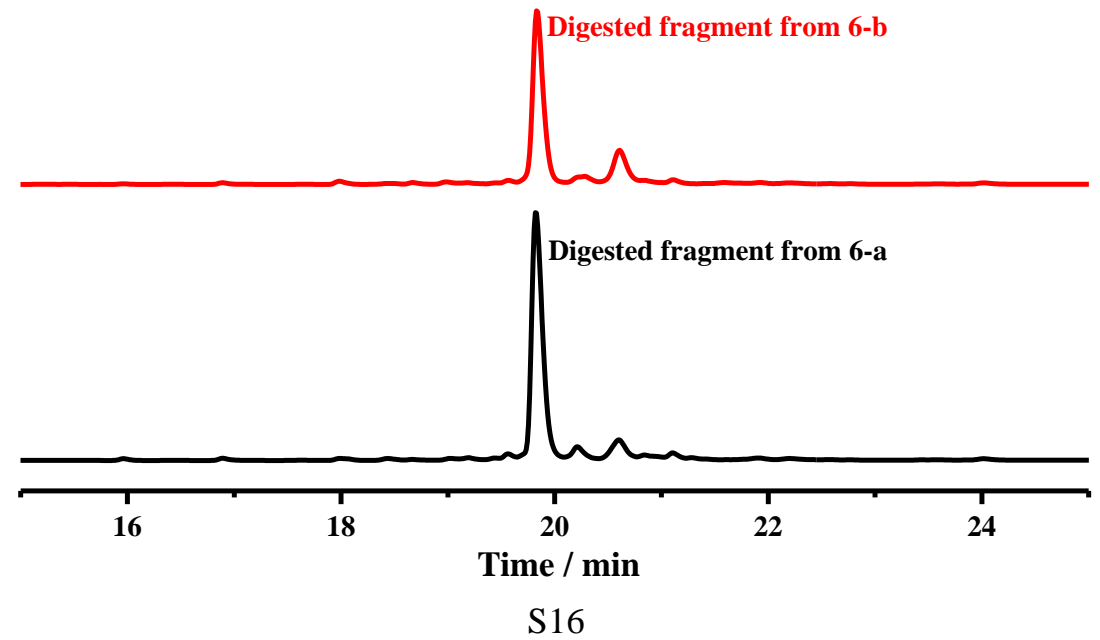


f)
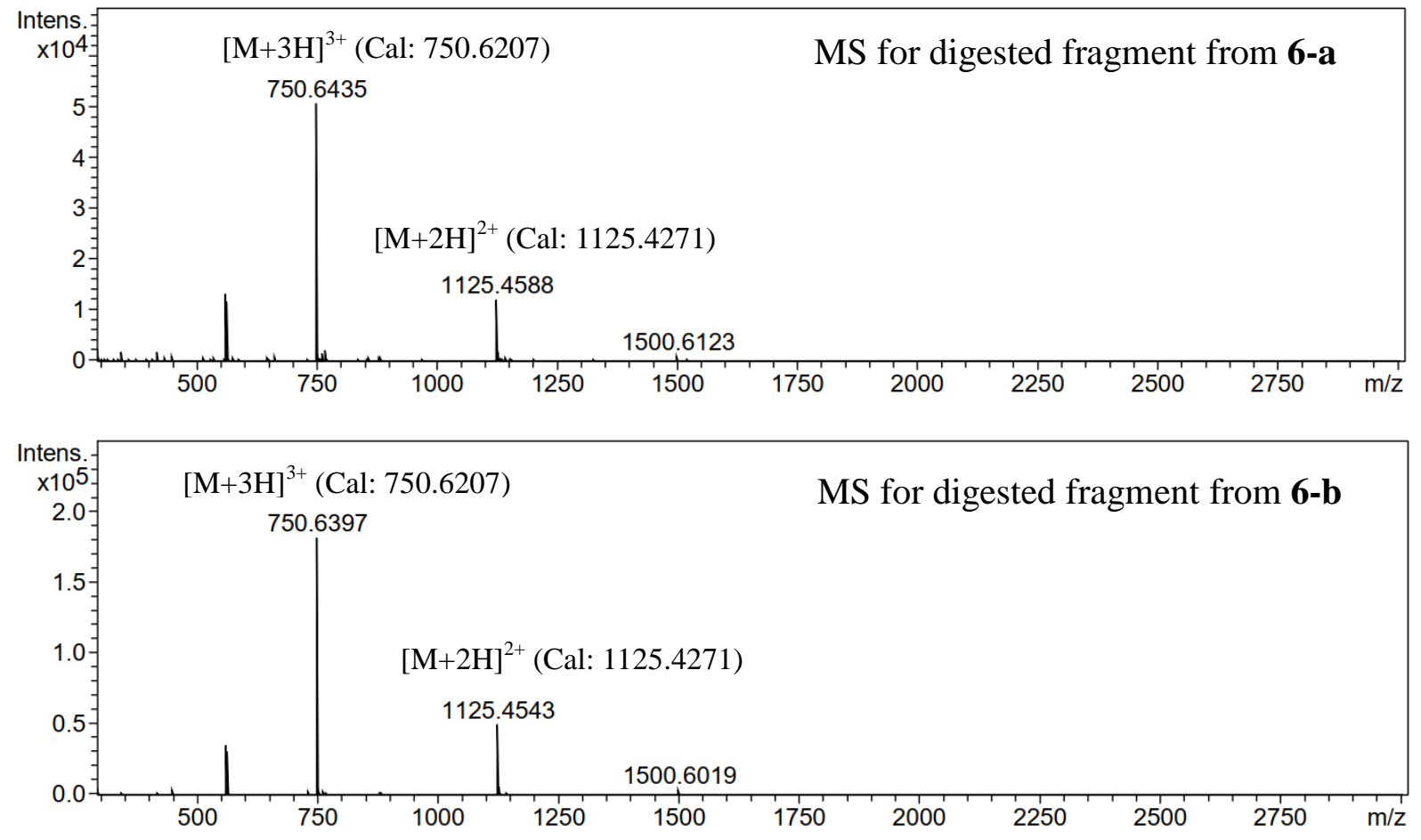

Figure S6. (a) Chromatogram of the products formed after the oxidation of peptide 6. (b) MS characterization of the products formed after the oxidation of peptide 6. (c) Chromatogram showing the confirmation of disulfide connectivity within peptide $\mathbf{6}$ through the orthogonal protecting group strategy; (black line) oxidative product; (red line) standard product. (d) MS characterization of standard products produced after removing Acm groups of oxidative peptide S6. (e) Chromatogram of digested fragments from 6-a (black line) and 6-b (red line). (f) Mass spectra of digested fragments from 6-a and 6-b labeled in the chromatogram, respectively.

The arrows indicate the cleavage sites of trypsin digestion:

\section{WGCGGKן̧GGPenGCGPenGCGGWK్GPenGW-NH}




\section{Oxidative Folding of Peptide 9}

a)

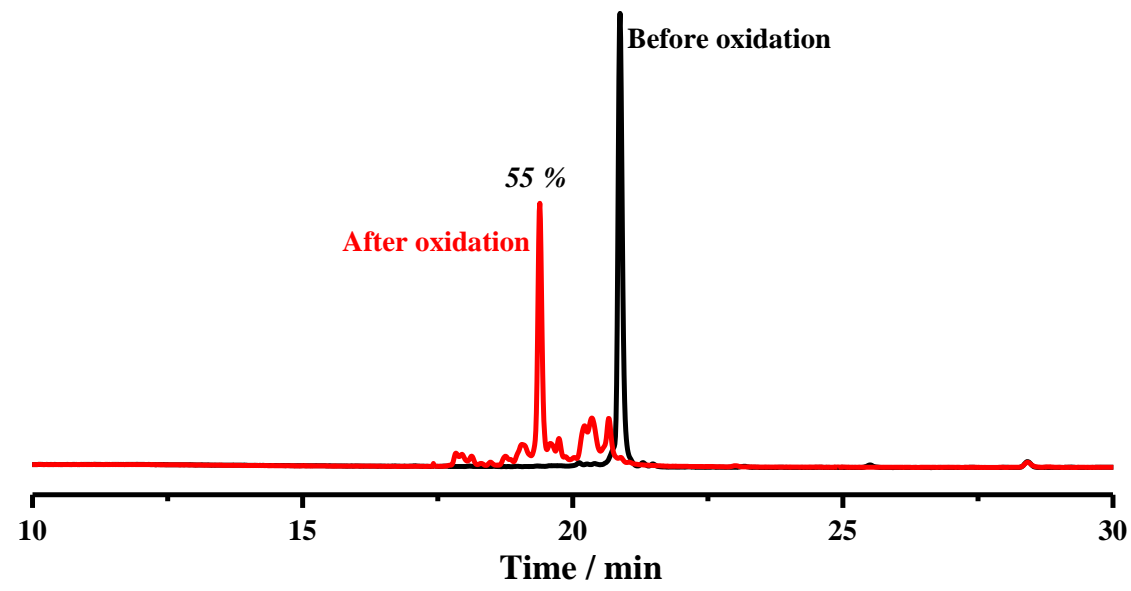

b)

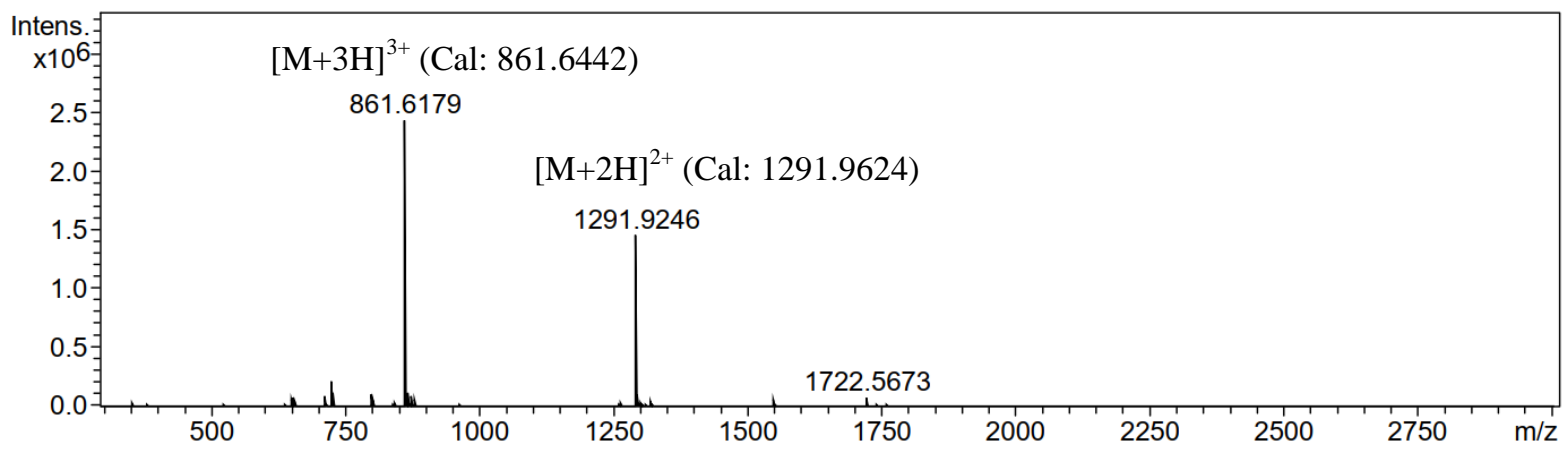

Figure S7. (a) Chromatogram showing the oxidation of peptide 9 in $100 \mathrm{mM}$ phosphate buffers containing 6 $\mathrm{M} \mathrm{Gu} \cdot \mathrm{HCl}$ and $0.5 \mathrm{mM}$ GSSG; (black line) reducing peptide; (red line) after $3 \mathrm{~h}$ oxidation; yield was calculated by comparing to the peak area of the reducing peptide. (b) MS characterization of the product formed after the oxidation of peptide 9 . 
8. Analysis of Disulfide Pairing of Peptide 9 Through the Orthogonal Protecting Group Strategy

a)

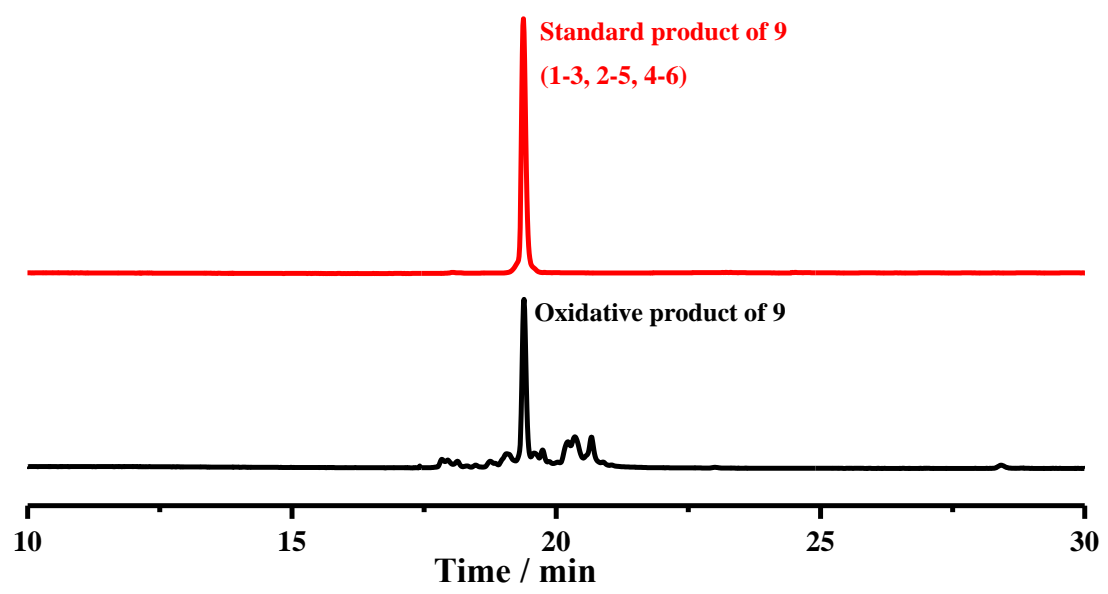

b)

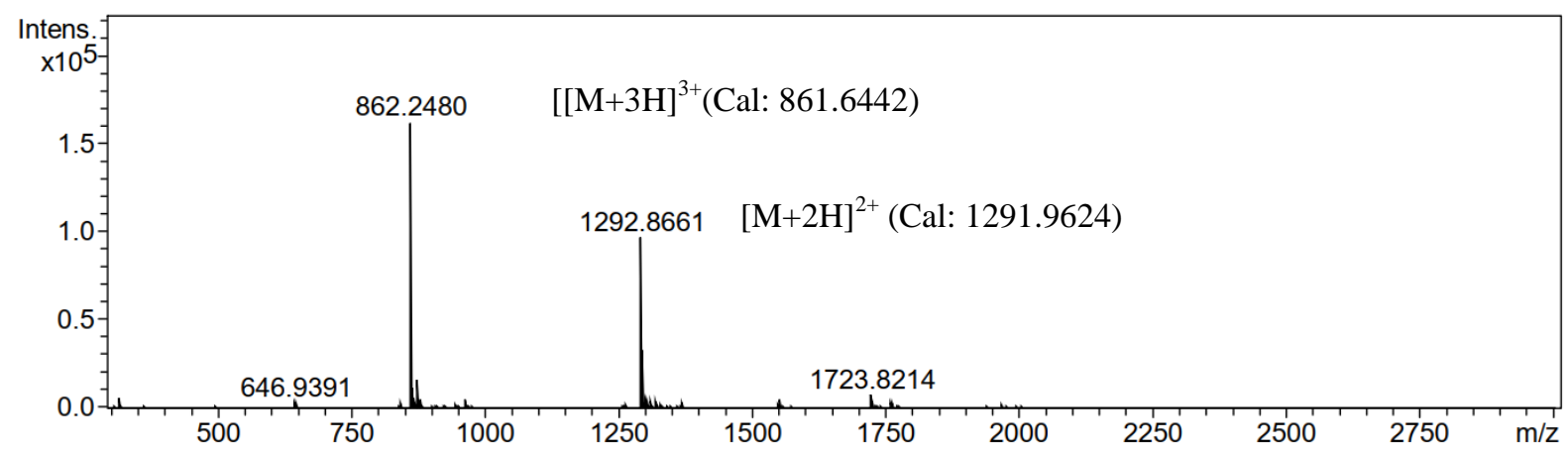

Figure S8. (a) Chromatogram showing the confirmation of disulfide pairing of peptide 9 through the orthogonal protecting group strategy; (black line) oxidative product; (red line) standard product. (b) MS characterization of the standard product formed after removing Acm groups of oxidative peptide S9. 


\section{The Inhibition of U87MG Cell Adhesion}

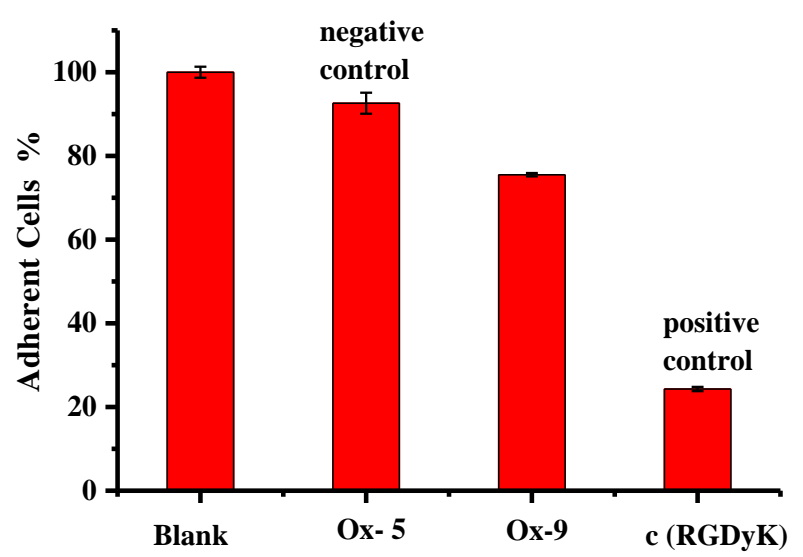

Figure S9. The bar chart shows the inhibition of U87MG cell adhesion by the Oxidative peptide 5 (Ox-5), oxidative peptide 9 (Ox-9) and $\mathrm{c}(\mathrm{RGDyK})$; oxidative peptide 5 served as negative control while commercially available c(RGDyK) was the positive control; the error bars represent the standard deviation of the mean $(\mathrm{n}=3)$. 


\section{Oxidative Folding of Peptide 10}

a)

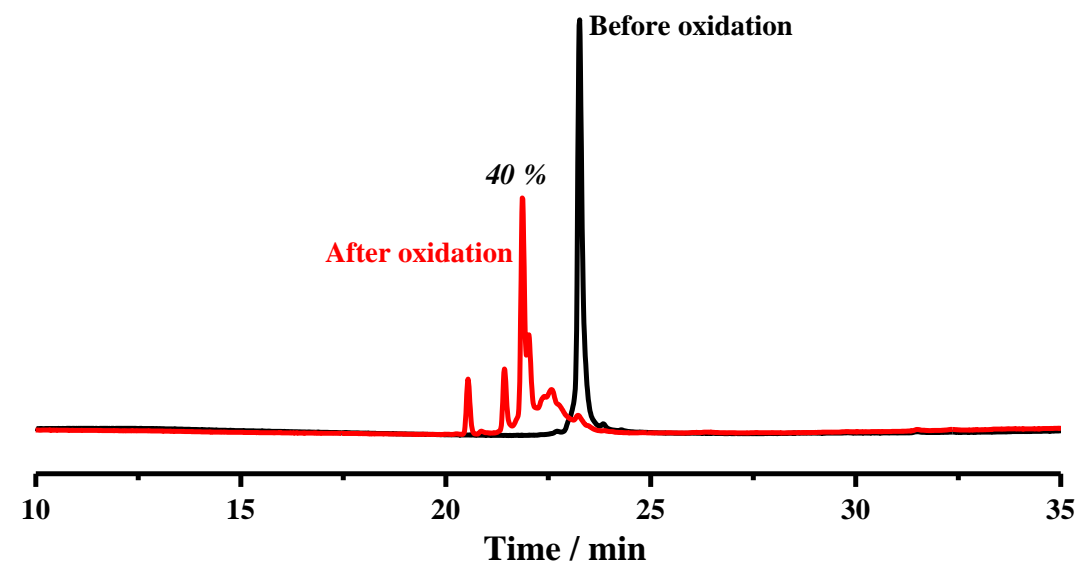

b)

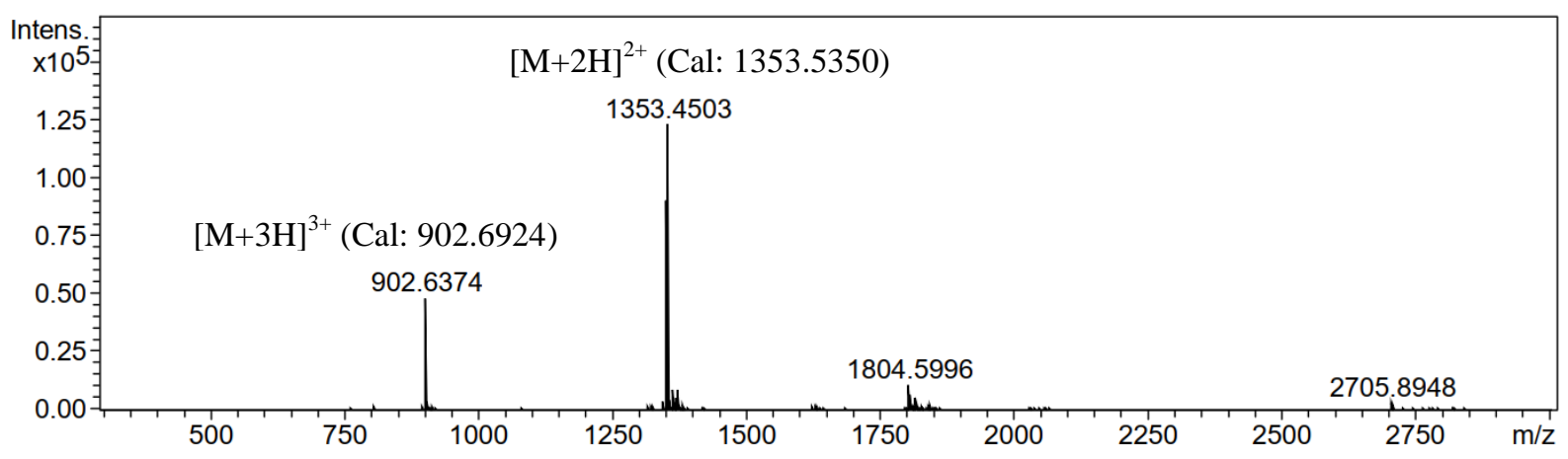

Figure S10. (a) Chromatogram showing the oxidation of peptide 10 in $100 \mathrm{mM}$ phosphate buffers containing $6 \mathrm{M} \mathrm{Gu} \cdot \mathrm{HCl}$ and $0.05 \mathrm{mM} \mathrm{Sec-Sec}$; (black line) reducing peptide; (red line) after $3 \mathrm{~h}$ oxidation; yield was calculated by comparing to the peak area of the reducing peptide. (b) MS characterization of the major product formed after the oxidation of peptide $\mathbf{1 0}$. 
a)

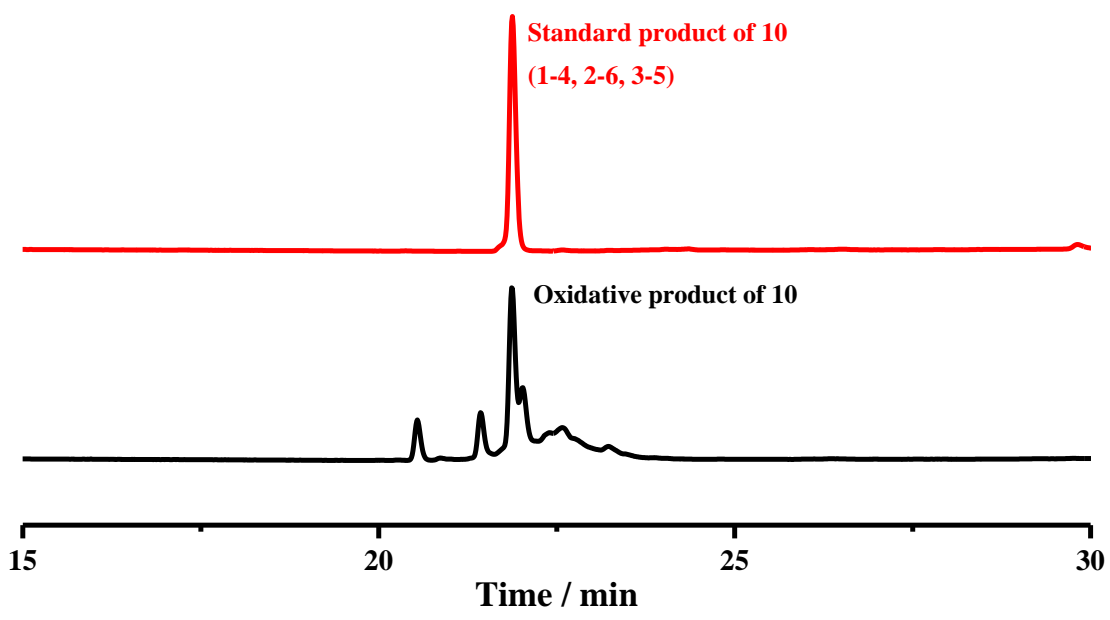

b)

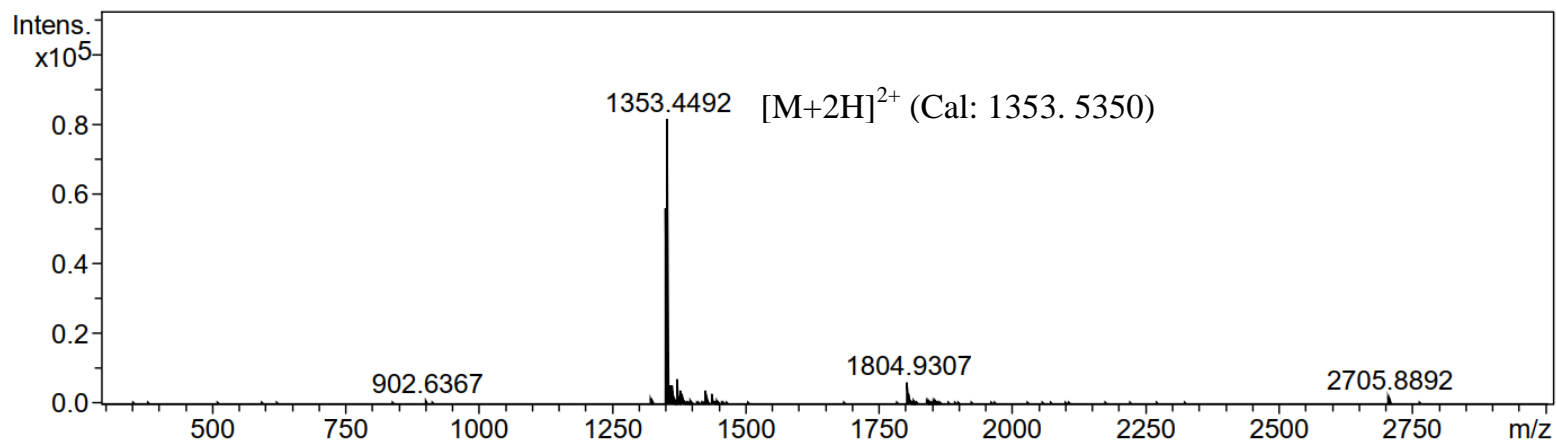

Figure S11. (a) Chromatogram showing the confirmation of disulfide pairing of peptide 10 through the orthogonal protecting group strategy; (black line) oxidative product; (red line) standard product. (b) MS characterization of the standard product formed after removing Acm groups of oxidative peptide S10. 


\section{Oxidative Folding of Peptide 11}

a)

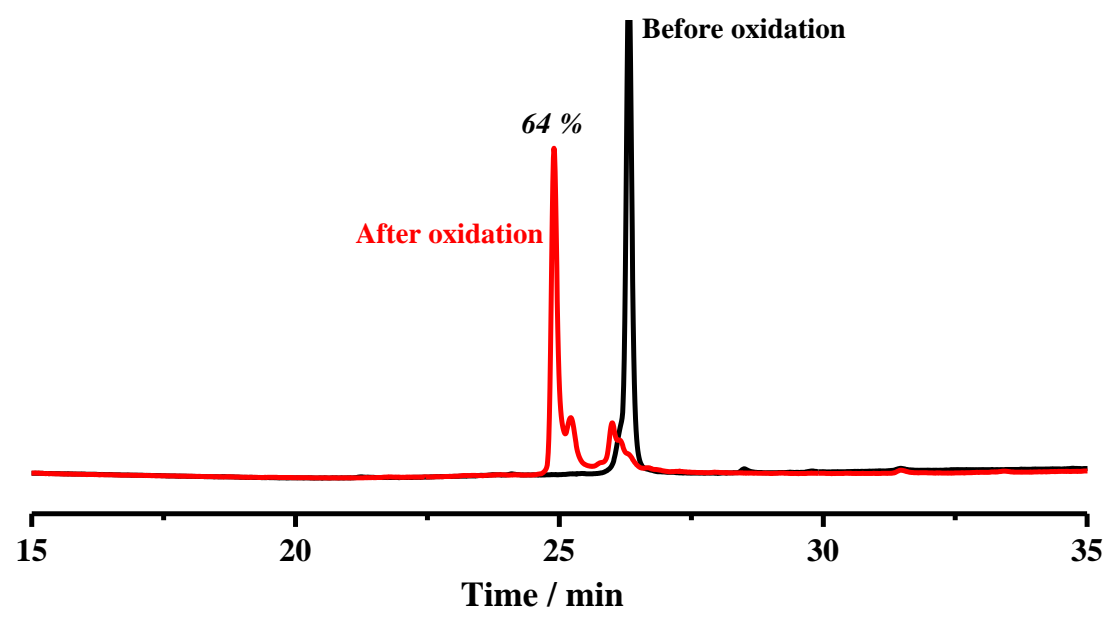

b)

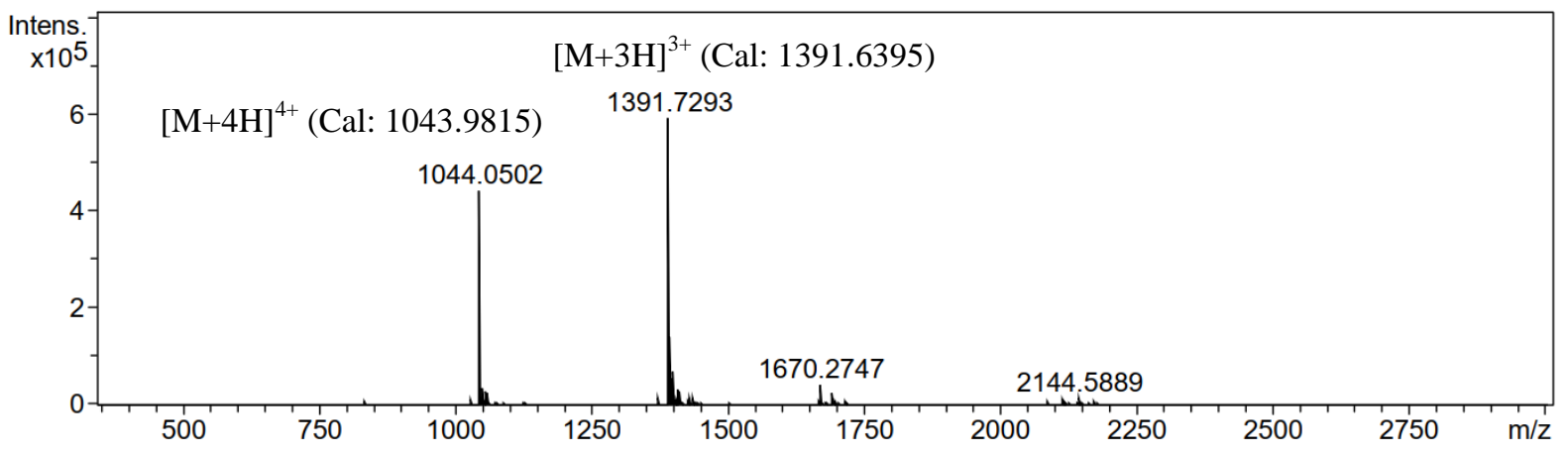

Figure S12. (a) Chromatogram showing the oxidation of peptide 11 in $100 \mathrm{mM}$ phosphate buffers containing $6 \mathrm{M} \mathrm{Gu} \cdot \mathrm{HCl}$ and $0.05 \mathrm{mM} \mathrm{Sec-Sec}$; (black line) reducing peptide; (red line) after $3 \mathrm{~h}$ oxidation; yield was calculated by comparing to the peak area of the reducing peptide. (b) MS characterization of the product formed after the oxidation of peptide $\mathbf{1 1}$. 
a)

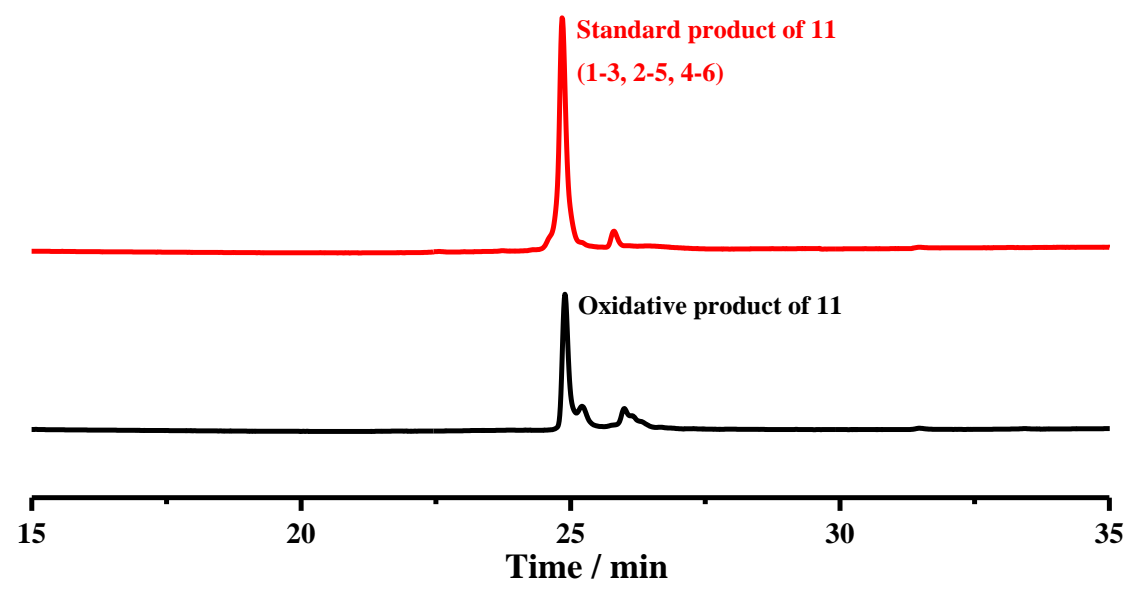

b)

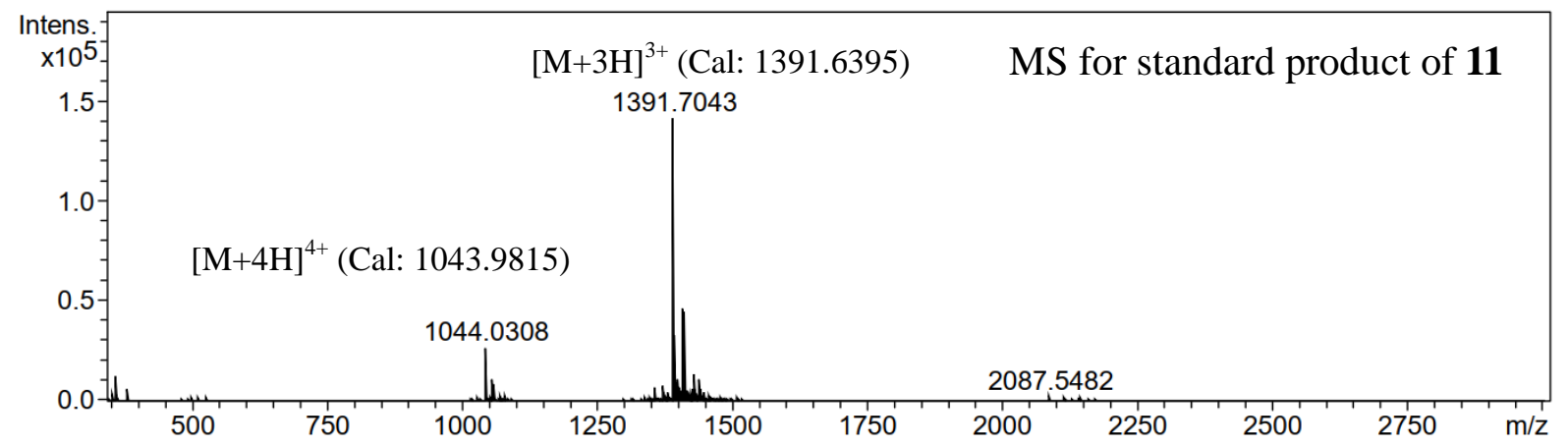

Figure S13. (a) Chromatogram showing the confirmation of disulfide connectivity of peptide $\mathbf{1 1}$ through the orthogonal protecting group strategy; (black line) oxidative product; (red line) standard product. (b) MS characterization of the standard product formed after removing Acm groups of oxidative peptide S11. 
14. Kinetics of Peptide 10 and 11 Degradation by Chymotrypsin in Tris-HCl Buffer at pH 7.8

a)

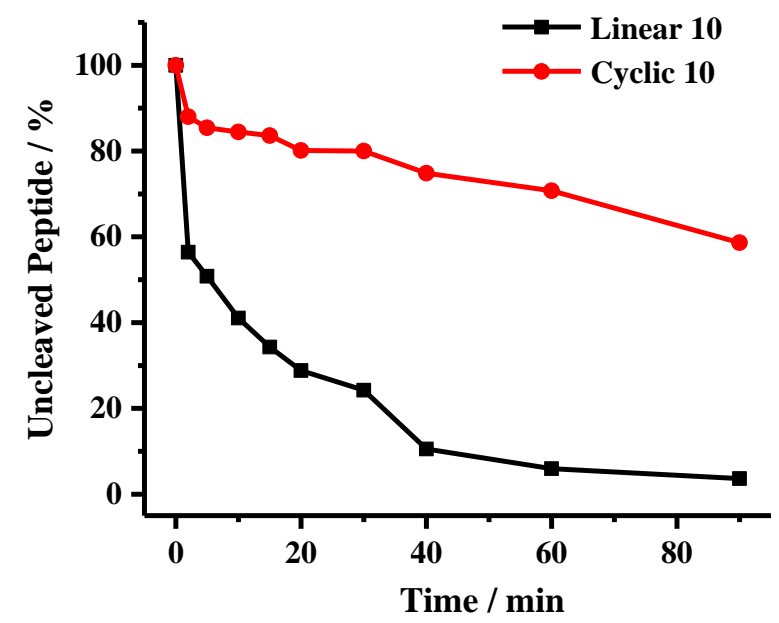

b)

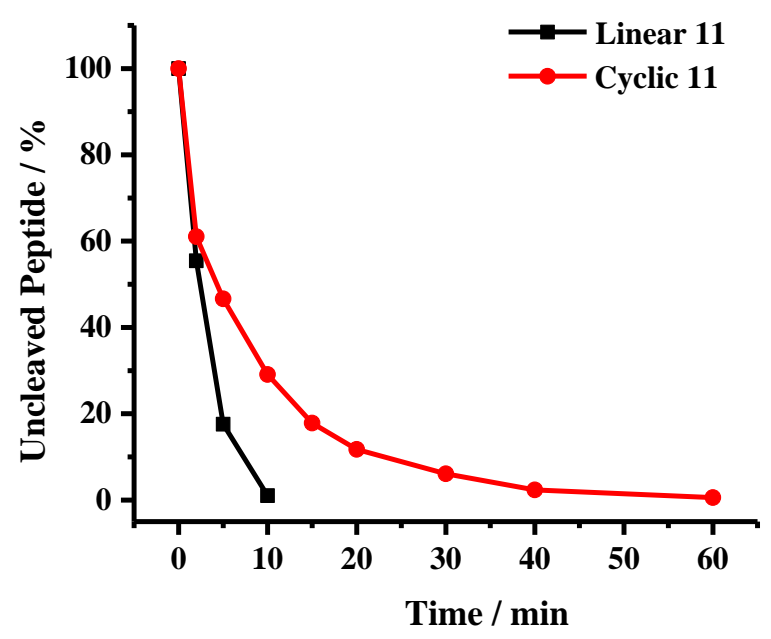

Figure S14. (a) Chromatogram showing the kinetics of peptide 10 degradation by chymotrypsin in Tris- $\mathrm{HCl}$ buffer at pH 7.8; (black line) degradation kinetic of linear peptide 10; (red line) degradation kinetic of cyclic peptide 10. (b) Chromatogram showing the kinetics of peptide $\mathbf{1 1}$ degradation by chymotrypsin in Tris- $\mathrm{HCl}$ buffer at pH 7.8; (black line) degradation kinetic of linear peptide 11; (red line) degradation kinetic of cyclic peptide 11. 


\section{Oxidative Folding of Peptide 12 and 13 in GSSG Buffers}

a)

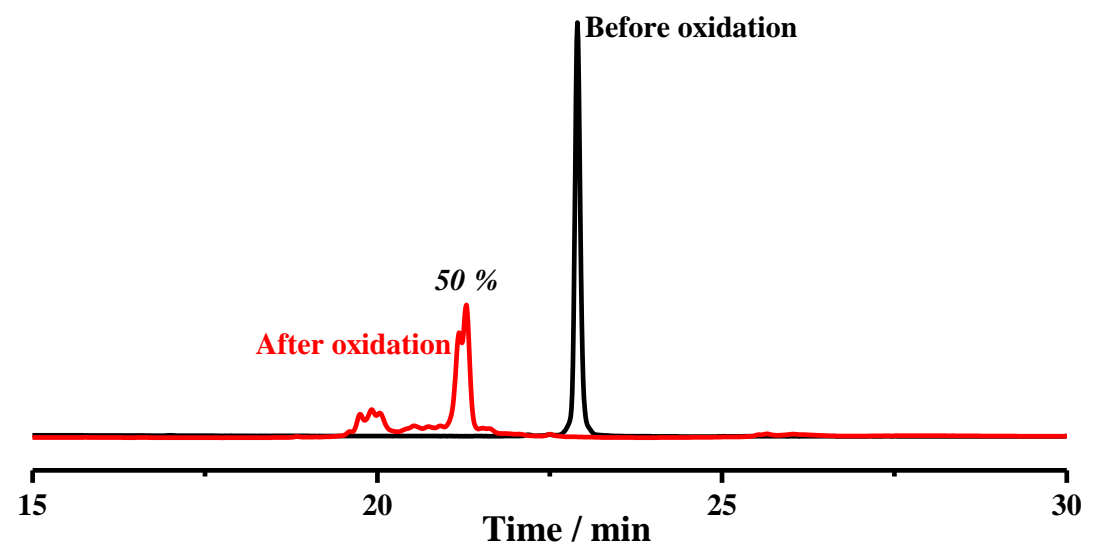

b)

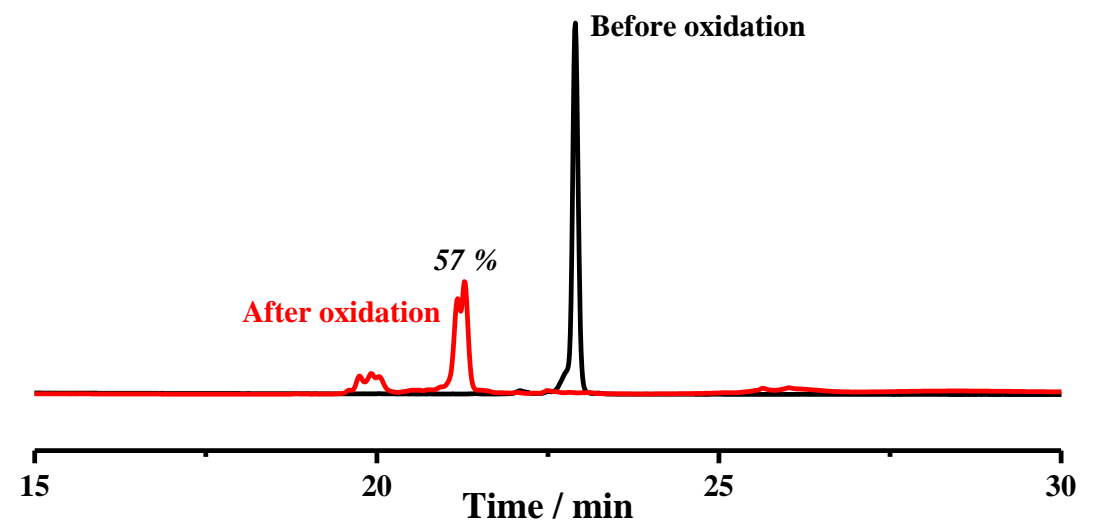

Figure S15. (a) Chromatogram showing the oxidation of peptide 12 in $100 \mathrm{mM}$ phosphate buffers containing $0.5 \mathrm{mM}$ GSSG; (black line) reducing peptide; (red line) after $3 \mathrm{~h}$ oxidation; yields were calculated by comparing to the peak area of the reducing peptides. (b) Chromatogram showing the oxidation of peptide 13 in $100 \mathrm{mM}$ phosphate buffers containing $0.5 \mathrm{mM} \mathrm{GSSG}$; (black line) reducing peptide; (red line) after $3 \mathrm{~h}$ oxidation. 
16. Analysis of Disulfide Pairing of Peptide 12 Through the Orthogonal Protecting Group Strategy

and Tryptic Digestion

a)

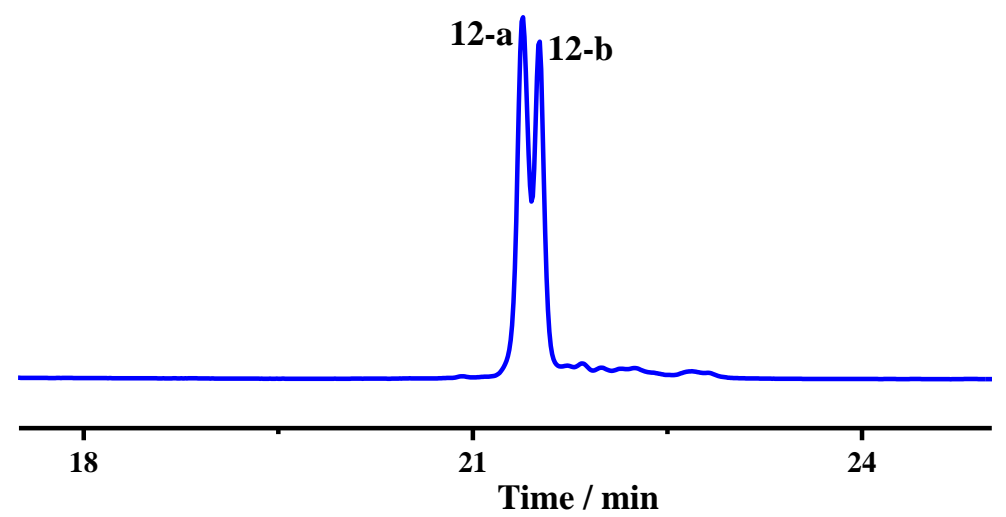

b)
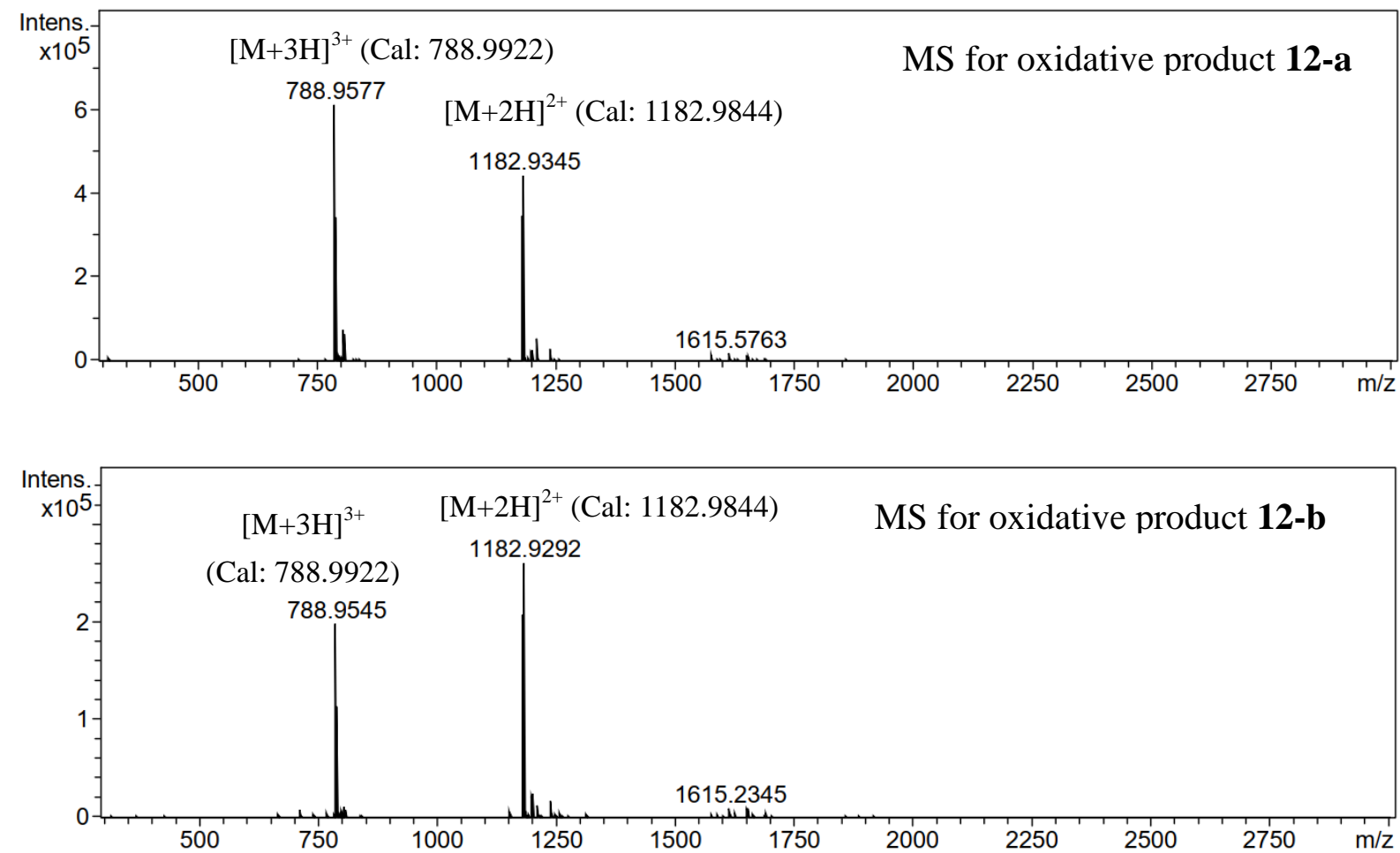


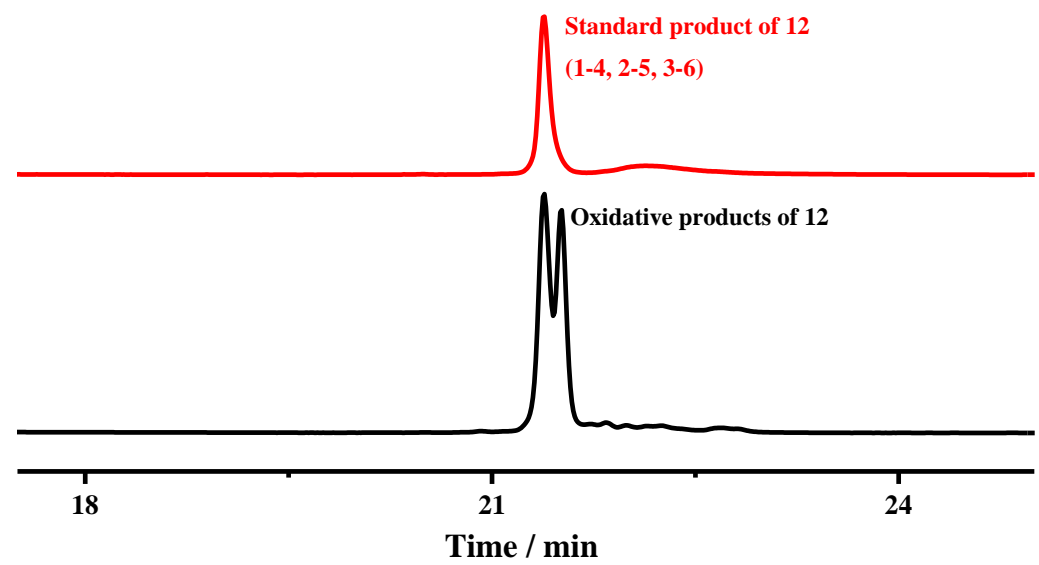

d)

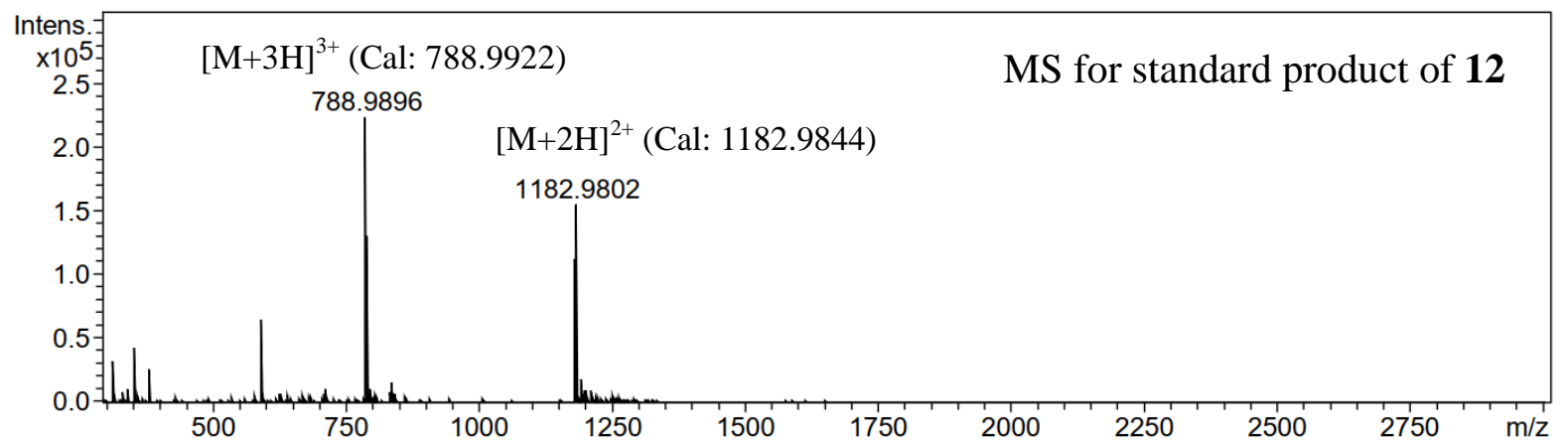

e)

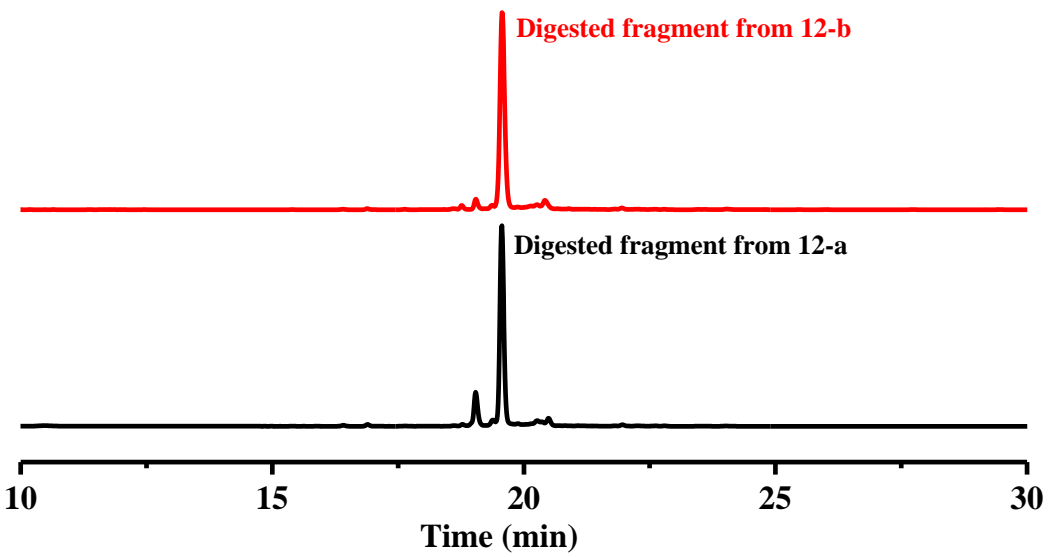



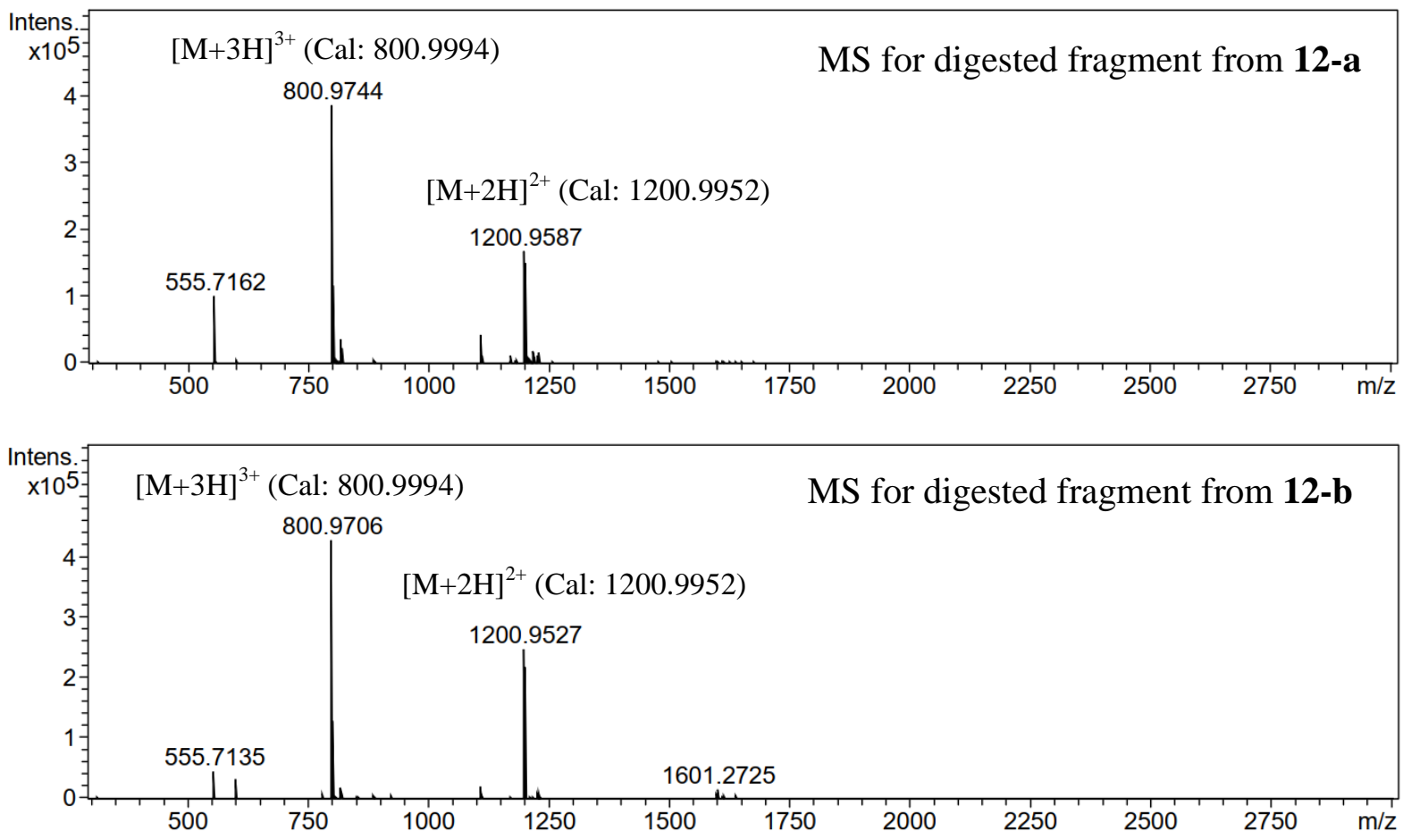

Figure S16. (a) Chromatogram of the products formed after the oxidation of peptide 12. (b) MS characterization of the products formed after the oxidation of peptide 12. (c) Chromatogram showing the confirmation of disulfide connectivity of peptide 12 through the orthogonal protecting group strategy; (black line) oxidative products; (red line) standard product. (d) MS characterization of the standard product formed after removing Acm groups of oxidative peptide S12. (e) Chromatogram of digested fragment from 12-a (black line) and 12-b (red line); (f) Mass spectra of digested fragments from oxidative peptide 12.

The arrows indicate the cleavage sites of trypsin digestion:

\section{WGCpPenK $K_{\downarrow}$ cPPenGGK ${ }_{\downarrow}$ GGPenGGWK}

Note that only two cleavage sites were recognized by trypsin, so we assumed that the lysine (K) located within this motif could not be cut easily due to the rigidity of cyclic peptide backbone. 
17. Analysis of Disulfide Pairing of Peptide 13 Through the Orthogonal Protecting Group Strategy and Tryptic

\section{Digestion}

a)

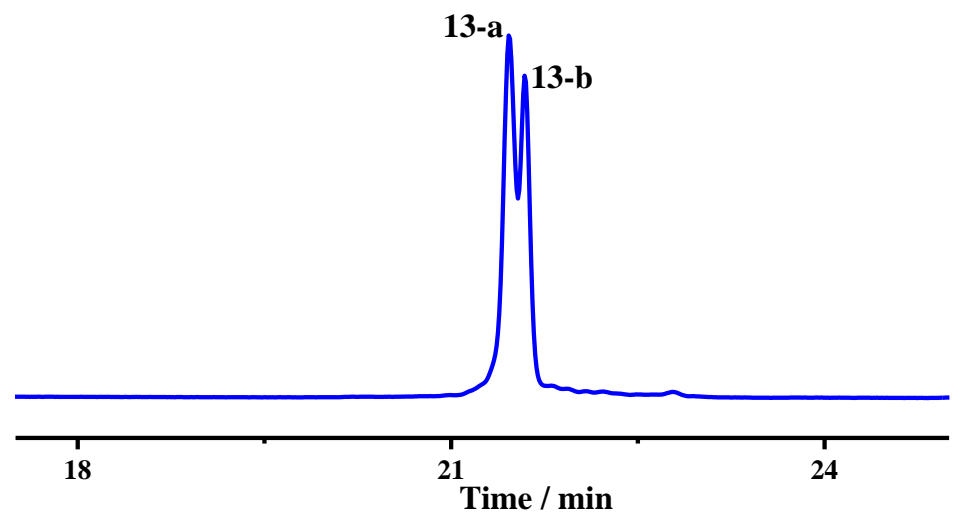

b)
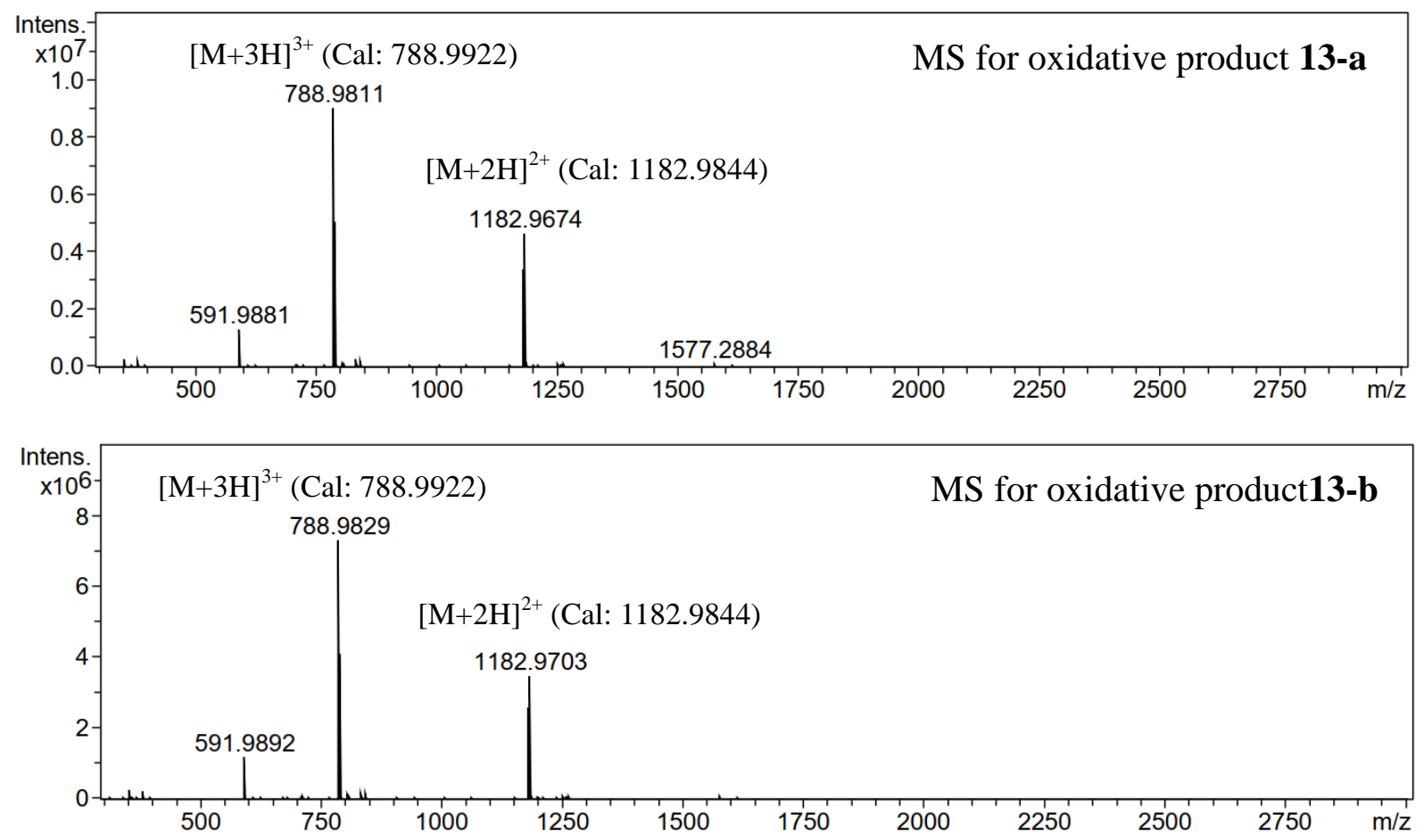


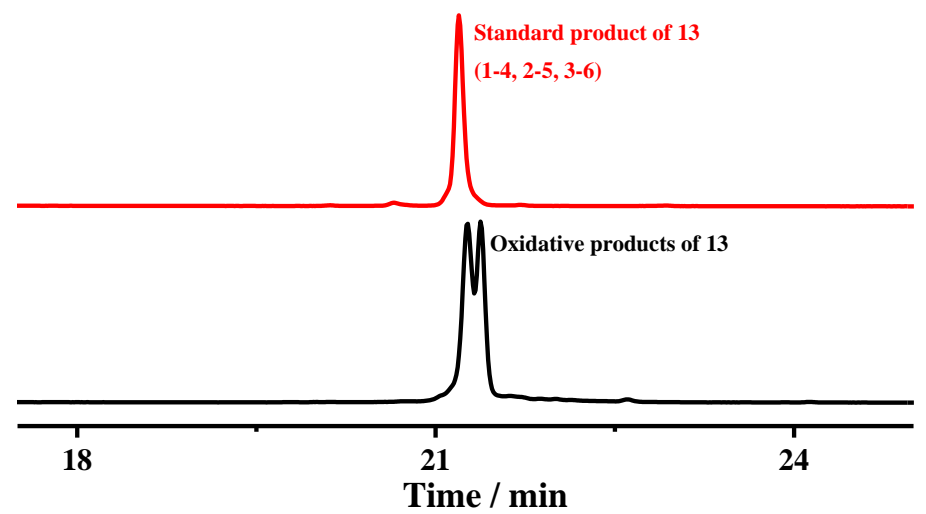

d)

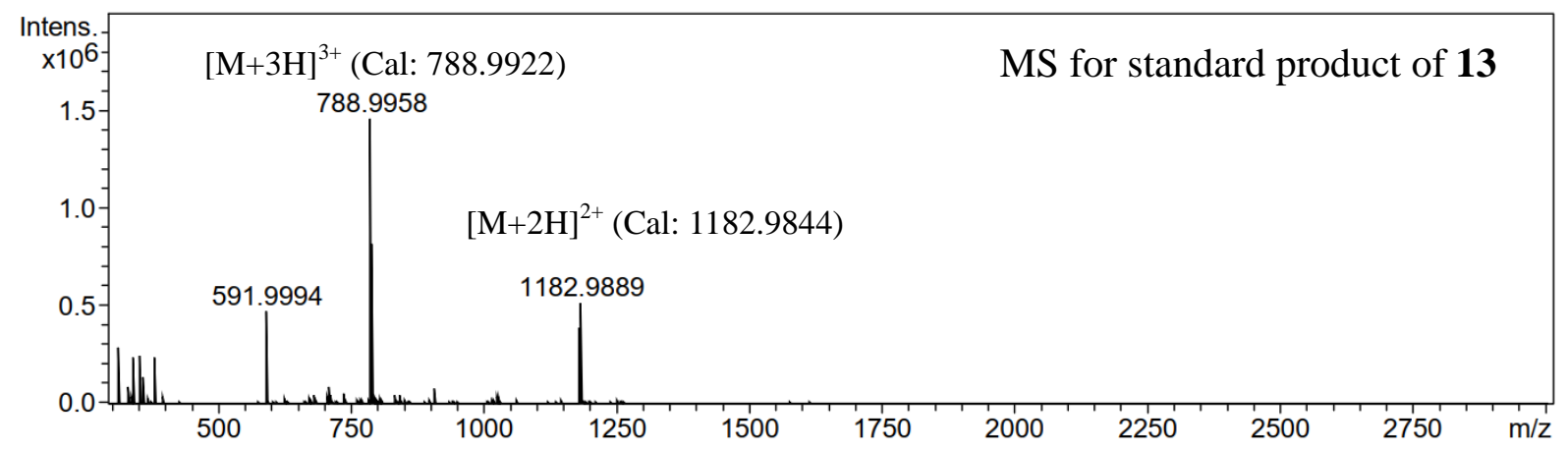

e)

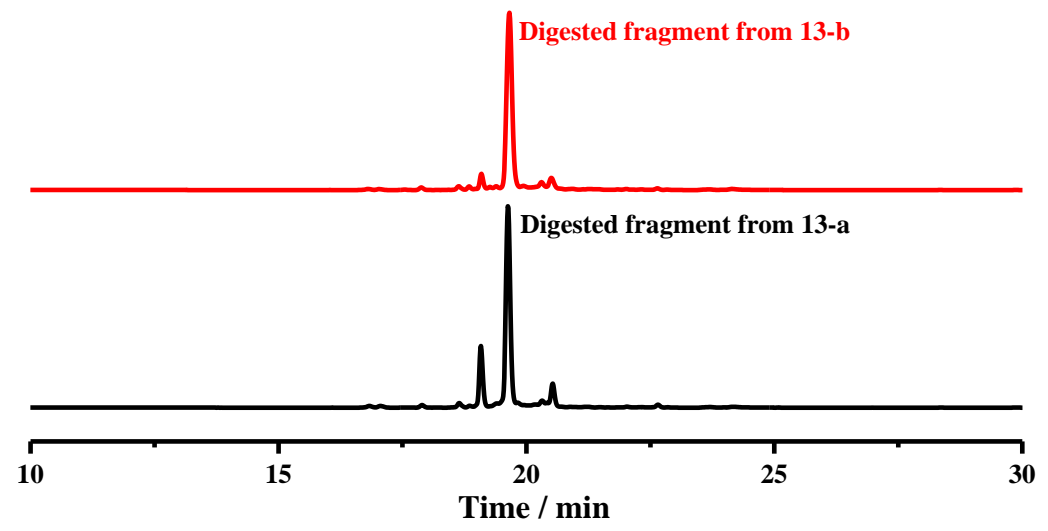



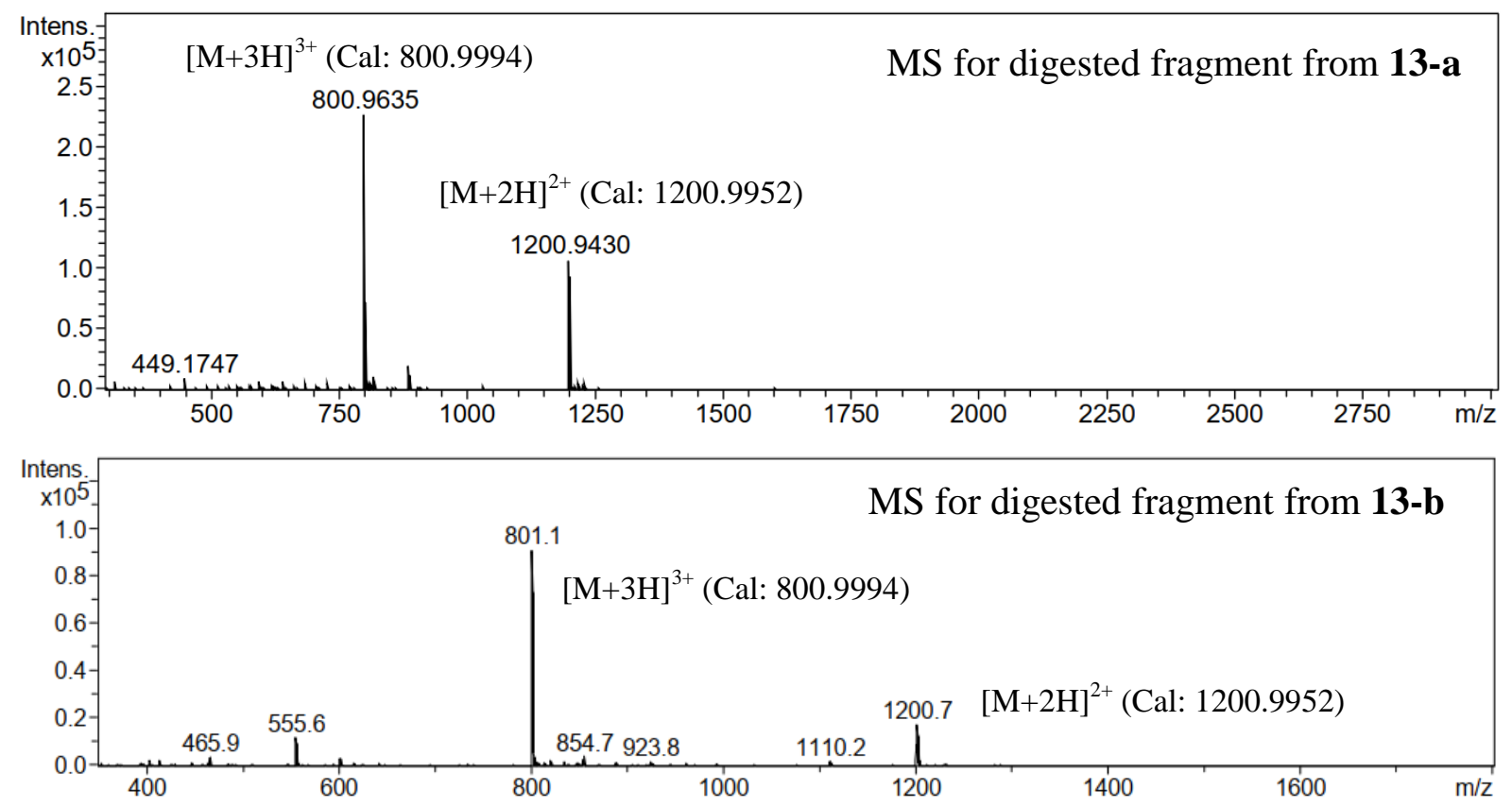

Figure S17. (a) Chromatogram of the products formed after the oxidation of peptide 13. (b) MS characterization of the products formed after the oxidation of peptide 13. (c) Chromatogram showing the confirmation of disulfide connectivity of peptide 13 through the orthogonal protecting group strategy; (black line) oxidative products; (red line) standard product. (d) MS characterization of the standard product formed after removing Acm groups of oxidative peptide S13. (e) Chromatogram of digested fragment from 13-a (black line) and 13-b (red line); (f) Mass spectra of digested fragments from oxidative peptide $\mathbf{1 3 .}$

The arrows indicate the cleavage sites of trypsin digestion:

\section{WGPenGGK ${ }_{\downarrow}$ GGCp PenK $K_{\downarrow}$ cPPenGGWK ${ }_{\downarrow}$ GCGW-NH}

Note that only two cleavage sites were recognized by trypsin, so we assumed that the lysine (K) located within this motif could not be cut easily due to the rigidity of cyclic peptide backbone. 